\title{
Ecoturismo e Arranjo Produtivo Local: uma análise da sustentabilidade ambiental em Itacaré (BA)
}

\section{Ecotourism and Local Productive Arrangement: an analysis of environmental sustainability in Itacaré (BA, Brazil)}

\author{
Wilson Alves de Araújo, Mônica de Moura Pires
}

RESUMO: O objetivo geral deste artigo é analisar a sustentabilidade ambiental do turismo na Bahia, sob a ótica do desenvolvimento local, tomando como referência o município de Itacaré que tem vivenciado nos anos 2000 uma "explosão" dessa atividade. Insere-se o aspecto ambiental em função de que o turismo desenvolvido no município está fortemente associado ao meio ambiente local. Parte-se assim dos intensos debates acerca das relações entre desenvolvimento e meio ambiente, propondo-se uma abordagem interdisciplinar baseada na problemática ambiental, especificamente a respeito das externalidades derivadas da atividade econômica exercida pelo homem sobre o meio natural, aqui tratada pela ótica da atividade turística. Em termos metodológicos, faz-se uso da pesquisa descritiva e metodológica, a partir da análise bibliográfica e de pesquisa de campo. Foram entrevistados e solicitados a responder ao questionário estruturado 30 empreendedores, diretores e gerentes das empresas que atuam no setor de hospedagem, no período de 13 a 21 de junho 2016, na localidade de Itacaré, Bahia. Esse destino turístico está inserido na Costa do Cacau, onde prevalece a prática do Ecoturismo. Este se diferencia, dos demais segmentos do turismo, por se apoiar em valores que reforçam o compromisso com a preservação ambiental e a interação com a comunidade local. Para tanto, a pesquisa privilegia dois recortes metodológicos: um recorte quantitativo, denominado Quociente Locacional (QL) e, um recorte analítico, utilizado para a caracterização de aglomerações produtivas em regiões de baixo e médio desenvolvimento, denominado Arranjo Produtivo Local (APL). Diante das análises realizadas, concluiu-se que a localidade estudada pode ser identificada como APL de turismo em fase de consolidação. $\mathrm{Na}$ dimensão ambiental constatou-se a necessidade de implementação de ações, públicas e privadas, que direcionem e potencializem medidas que elevem a atividade turística de forma sustentável. Especificamente, relacionadas a redução do consumo de água e energia, aproveitamento da água da chuva, gerenciamento de resíduos sólidos e implementação de coleta seletiva. Esperase como resultado deste trabalho, subsidiar o desenvolvimento de políticas públicas direcionadas ao desenvolvimento sustentável do turismo.

PALAVRAS-CHAVE: Turismo; Clusters; Desenvolvimento Local; Indicadores de Sustentabilidade; Meio Ambiente. 


\section{ABSTRACT}

The general objective of this article is to analyze the environmental sustainability of tourism in Bahia under the perspective of local development, taking as reference the municipality of Itacaré, which has experienced in the year 2000 an "explosion" of this activity. The environmental aspect is inserted because tourism developed in the municipality is strongly associated with the local environment. It is based on the intense debates about the relationship between development and the environment, proposing an interdisciplinary approach based on the environmental issue, specifically on the externalities derived from economic activity carried out by the man on the natural environment, here treated by the view of tourist activity. In methodological terms, descriptive and methodological research is used, from bibliographic analysis and field research. Thirty entrepreneurs, directors and managers of companies operating in the lodging sector were interviewed and asked to respond to the structured questionnaire, from June 13 to 21,2016 , in the city of Itacaré, Bahia. This tourist destination is inserted in the Cacao Coast where the practice of Ecotourism prevails. This is different from other tourism segments, because it relies on values that reinforce the commitment to environmental preservation and interaction with the local community. For this, the research privileges two methodological cuts: a quantitative cut, called Locational Quotient (QL) and, an analytical cut, used for the characterization of productive agglomerations in low and medium development regions, denominated Local Productive Arrangement (APL). In view of the analysis carried out, it was concluded that the studied locality can be identified as APL of tourism in consolidation phase. In the environmental dimension, it was verified the need to implement public and private actions that direct and potentiate measures that increase tourism activity in a sustainable manner. Specifically, related to reduction of water and energy consumption, use of rainwater, solid waste management and implementation of selective collection. As a result of this work, it is hoped to support the development of public policies directed to the sustainable development of tourism.

KEYWORDS Tourism; Clusters; Local Development; Sustainability Indicators; Environment. 


\section{Introdução}

O presente trabalho baseia-se em uma abordagem interdisciplinar a respeito da problemática ambiental considerando-se as discussões entre desenvolvimento e meio ambiente. Nesse contexto, a temática busca compreender as relações sistêmicas e dialéticas dos processos ambientais, em particular, dos impactos decorrentes da atividade econômica exercida pelo homem sobre o meio natural inserido no contexto da atividade turística na Costa do Cacau, localizada no sul da Bahia, especificamente, na localidade de Itacaré.

As características paisagísticas, climáticas e geográficas da Costa do Cacau, aliadas a exuberância de suas praias, proporcionam considerável movimento de turista em Itacaré. Desta forma, estas características possibilitam a prática do Turismo Cultural, Turismo de Aventura, Turismo de Sol e Praia, além do Ecoturismo predominante nesta região.

Neste sentido, este estudo destaca o Ecoturismo praticado nesta localidade, por tratar-se de uma atividade turística que utiliza, de forma sustentável, o patrimônio natural e cultural, fomenta sua conservação e demanda a formação de uma consciência ambientalista através da interpretação do ambiente, promovendo o bem-estar das populações e dos atores sociais locais (BRASIL, 2010; SPAOLONSE; MARTINS, 2017),

Devido ao seu potencial de crescimento e desenvolvimento e, por tratar-se de um fenômeno político, social, econômico e cultural na contemporaneidade The United Nations (UN) General Assembly, em 22 de dezembro de 2015, adotou a Resolução 70/193, estabelecendo 2017 como o Ano Internacional do Turismo Sustentável para o Desenvolvimento.

A Resolução reafirma o papel do turismo sustentável nos países em desenvolvimento, "como instrumento positivo para a erradicação da pobreza, a proteção do ambiente, a melhoria da qualidade de vida e o empoderamento econômico das mulheres e dos jovens", bem como, a sua contribuição para as três dimensões do desenvolvimento sustentável: econômico, social e ambiental (UN, 2016, p. 3). Neste sentido, define-se turismo sustentável "como aquele que atende às necessidades dos turistas de hoje e das regiões receptoras, ao mesmo tempo em que protege e amplia as oportunidades para o futuro" (WTO, 2003, p. 24).

O turismo é, por natureza, uma atividade que impulsiona e, ao mesmo tempo, depende do desenvolvimento regional e local sustentado. Discutido e abordado por várias ciências, atualmente vem sendo compreendido como elemento chave para a dinamização de regiões com baixo nível de desenvolvimento no mundo e, em especial, no Brasil.

Nas últimas décadas o conceito de desenvolvimento local tem sido apontado como uma proposta de desenvolvimento para questões relacionadas à compatibilidade entre ambiente, comunidades e sustentabilidade. Para Cassiolato, Lastres e Stallivieri (2008, p. 12) "a ênfase no local levou ao desenvolvimento do termo mais amplamente difundido de arranjos produtivos locais (APLs)". No Brasil, diversos estudos têm sido conduzidos com base teórico-metodológico para análise de APLs, com 
utilização de medidas de localização e especialização, como o Quociente Locacional (QL).

Este estudo é oportuno no sentido da emergência da temática dos clusters e APLs, como aglomerações produtivas passíveis de promover o desenvolvimento local. A identificação e análise do nível de sustentabilidade ambiental nestas aglomerações, com a utilização de indicadores de sustentabilidade, poderá contribuir para a mitigação dos impactos ambientais ocasionados pela atividade humana. Neste contexto, a interdependência e a participação dos atores locais no processo de desenvolvimento sustentável atribui importância aos APLs, como indutores do desenvolvimento local (MARINI; SILVA; NASCIMENTO, 2016).

A questão que se estabelece a partir do conceito de desenvolvimento sustentável é como identificar quais fatores e elementos fortalecem ou fragilizam a atividade turística em um local, sob a ótica da sustentabilidade? A resposta a esta pergunta tem sido a criação e a aplicação de sistemas ou ferramentas de avaliação que procuram mensurar a sustentabilidade.

Para a World Tourism Organization (WTO), os indicadores podem ter uma influência fundamental no processo do desenvolvimento sustentável do turismo por meio da informação que geram a partir da interação entre os atores; da mobilização que criam; e das ações que promovem. Portanto, esta pesquisa se centra nas atividades desenvolvidas pelas organizações do setor do turismo, consubstanciando-as na economia local (WTO, 2005). Espera-se assim, aumentar o conhecimento científico a respeito das relações entre desenvolvimento e meio ambiente.

Para Van Bellen (2002, p. 70), "[...] existe um razoável grau de consenso no que se refere à necessidade de desenvolvimento de metodologias que façam uma avaliação da sustentabilidade". A despeito da existência de diversos indicadores de sustentabilidade, verifica-se a ausência na literatura especializada de sistemas ou ferramentas que mensurem, simultaneamente, a aglomeração produtiva e a sustentabilidade das atividades econômicas, possibilitando mensurar 0 desenvolvimento sustentável dessas atividades, e especificamente neste trabalho da atividade turística.

Nesse sentido, o objetivo deste trabalho é analisar a sustentabilidade ambiental do turismo no município de Itacaré, Bahia, sob a ótica do desenvolvimento local. Esta pesquisa procura compreender e discutir 0 desenvolvimento sustentável de forma a contribuir na análise das políticas de desenvolvimento regional, particularmente, na localidade estudada, além de subsidiar a elaboração e o desenvolvimento de políticas públicas direcionadas ao turismo sustentável.

O presente artigo está estruturado em cinco seções. Inicialmente, além desta introdução, apresenta-se uma discussão teórica acerca dos principais conceitos utilizados neste estudo, destacando-se o referencial teórico sobre: Arranjo Produtivo local (APL); Turismo Sustentável; e Indicadores de Sustentabilidade. Na terceira seção são apresentados os procedimentos metodológicos. A seguir, na quarta seção, apresentam-se os 
resultados da pesquisa e, por fim, as conclusões e sugestões ocupam a última seção deste artigo.

\section{Arranjo Produtivo Local do Turismo: fundamentos conceituais}

O crescente interesse pelos aglomerados produtivos pode ser atribuído às mudanças no ambiente competitivo das empresas. Diversos conceitos são encontrados na literatura especializada, destacam-se: distritos industriais, clusters, sistemas locais de produção, APLs, entre outros, "que contêm diferenças entre si, mas têm como elo comum o entendimento de que as aglomerações, em sentido amplo, facilitam e contribuem para a dinâmica econômica e inovativa de um espaço territorial específico" (TATSCH et al., 2015, p. 194).

De acordo com Crocco et al. (2006, p. 217), as aglomerações produtivas são consideradas uma "valiosa forma de promover 0 desenvolvimento econômico. Daí a importância de se desenvolver metodologias que ajudem os gestores de políticas de desenvolvimento a identificar o surgimento dessas aglomerações". Albagli e Brito (2003, p. 7) definem algumas das características que tipificam a aglomeração produtiva. Para os autores "o termo aglomeração - produtiva, científica, tecnológica e/ou inovativa - tem como aspecto principal a proximidade territorial de agentes econômicos, políticos e sociais". Esses agentes econômicos utilizam-se das vantagens oriundas da proximidade geográfica, incluindo acesso a matérias-primas, equipamentos, mão-de-obra e outros, e formam as denominadas economias de aglomeração.

De acordo com Parr (2002), observa-se que na área da política urbana e regional o conceito de economias de aglomeração se encontra no centro das estratégias de desenvolvimento. Portanto, é fundamental que o conceito seja definido claramente $e$, que as pesquisas sobre o tema contribuam para realçar este conceito de forma consistente. Desta forma, os conceitos e instrumentais ora apresentados nesta pesquisa pretendem fornecer um referencial teórico e metodológico para o entendimento do desenvolvimento local, considerando-se os arranjos produtivos locais como indutores desse processo.

Segundo Moreira, Fernandes e Dias Junior (2017, p. 59), "[...] A partir dos conceitos encontrados na literatura, pode-se perceber e identificar algumas características para os aglomerados produtivos, consoante o seu grau de desenvolvimento [...]". Neste sentido, no que se refere à classificação de Arranjos Produtivos quanto ao grau de desenvolvimento, o Ministério de Ciência e Tecnologia (MCT), classifica-os pelos seguintes critérios:

(i) Arranjo Elementar - Destaca-se pela existência, em determinada localidade ou região, de uma concentração de unidades produtoras com alguma característica em comum, indicando a existência de tradição técnica ou produtiva (inclusive artesanal), mas com grau de especificidade ou originalidade suficiente apenas para garantir a subsistência do mesmo; 
(ii) Arranjo em Fase de Consolidação - Destaca-se pela existência no local ou região de atividades produtivas com características comuns, pela existência de uma infraestrutura tecnológica significativa, bem como a existência de relacionamentos dos agentes produtivos entre si e com os agentes institucionais locais consolidando a geração de sinergias e externalidades positivas, mas ainda com a presença de conflitos de interesses e/ou desequilíbrios denotando baixo grau de coordenação e de visão estratégica; e,

(iii) Arranjo Consolidado - Possui todas as características do agrupamento anterior, mas com alto nível de coesão e organização entre os agentes. Os Arranjos Produtivos Consolidados são representados por concentrações geográficas de empresas de um setor econômico particular, criando assim, uma infraestrutura produtiva especializada e inovadora. Nas articulações institucionais estão presentes órgãos governamentais e outras instituições, tais como universidades, escolas técnicas, agências de fomento e associações profissionais, que fornecem treinamento especializado, educação, informação, pesquisa e suporte técnico (CALIMAN, 2003).

No Brasil, estudos sobre aglomerações produtivas vêm sendo incentivados por órgãos públicos de fomento à pesquisa como o Banco Nacional de Desenvolvimento Econômico e Social (BNDES), Ministério da Ciência e Tecnologia (MCT) e suas agências: Financiadora de Estudos e Projetos (FINEP) e Conselho Nacional de Desenvolvimento Científico e Tecnológico (CNPq). Merece destaque, ainda, a Rede de Pesquisa em Sistemas Produtivos e Inovativos Locais (REDESIST), do Instituto de Economia da Universidade Federal do Rio de Janeiro (UFRJ) e o Centro de Desenvolvimento e Planejamento Regional (CEDEPLAR) da Universidade Federal de Minas Gerais (UFMG) que vêm promovendo estudos sobre Arranjos Produtivos Locais (APLs).

Considerando-se a capilaridade dos APLs no Brasil e a atividade turística desenvolvida na Costa do Cacau, com o consequente impacto no meio ambiente, estima-se que a utilização de novos indicadores que mensurem o grau de concentração e o nível de sustentabilidade ambiental poderão contribuir para a mitigação desses impactos. De acordo com Moreira (2013, p. 122), "justifica-se, assim, a continuidade da pesquisa nesta área, seja no desenvolvimento de novas propostas de indicadores ou na avaliação dos indicadores já existentes".

A ideia de pesquisar e analisar o turismo como um sistema de clusters e/ou APLs, está presente em vários estudos acadêmicos, Ferreira et al. (2011), Costa, Costa e Miranda Jr (2012), Alberti e Giusti (2012), ArsezenOtamis e Yuzbasioglu (2013) e Souza e Gil (2014), especialmente vinculados à temática do desenvolvimento local e regional.

O turismo é uma atividade econômica, diferentemente das demais pelo fato de ser produzido e consumido no mesmo local, levando o consumidor a se deslocar para poder usufrui-lo (BENI, 2002). Para tanto, são ofertados um conjunto composto de bens e serviços - tangíveis e intangíveis - a fim de satisfazer as necessidades e expectativas dos consumidores (turistas). Os referidos bens e serviços são produzidos nas 
diversas unidades produtoras, que, normalmente, são transformados ao longo da cadeia produtiva até o consumo final pelo turista.

De acordo com o SEBRAE (2008) a atividade turística interage com 52 outras atividades produtivas da economia, constituindo, portanto, uma malha ampla e complexa de encadeamento. Como cadeia produtiva, o turismo foi organizado em três grandes blocos. O conjunto de atividades diretamente vinculadas ao negócio turístico expressa um encadeamento que tem como âncora a atividade definida pelo Instituto Brasileiro de Geografia e Estatística (IBGE) como "Alojamento e alimentação" (CNAE 5510-8/01). Esta cadeia produtiva do turismo gera várias demandas de insumos e serviços, a montante, e promove diferentes desdobramentos a jusante. Ela é formada por uma diversidade de segmentos turísticos, destacando-se: turismo de praia e sol, aventura, eventos e negócios, cultural e científico, religioso, terceira idade, ecoturismo, entre outros.

Sobre o pensamento conceitual do Ecoturismo, Cruz, Mendes e Campos (2017, p. 738) asseveram que "[...] historicamente, constrói-se tendo como base princípios de desenvolvimento, meio ambiente, sustentabilidade e proteção dos recursos, sejam eles naturais, sociais e culturais". Desta forma, verifica-se que o Ecoturismo tem forte apelo ambiental e prevalece como atividade turística na Costa do Cacau.

Para Spaolonse e Martins (2017, p. 687), na atividade turística se enfatiza a mitigação de impactos, "uso de recursos de forma responsável, envolvimento das comunidades em suas práticas, é apresentado enquanto um conceito que se constrói a partir de compromissos e pactos tendo como base o desenvolvimento local'. Daí, verifica-se então a importância e premência das políticas públicas no desenvolvimento da atividade turística no Brasil e, em especial, nas regiões costeiras onde a presença das Unidades de Conservação (UCs) possibilitam a preservação do bioma Mata Atlântica. Neste caso, quando se observa que o desenvolvimento local é inserido como uma categoria fundamental ao Ecoturismo, no que diz respeito ao planejamento e operacionalização, Cruz, Mendes e Campos concebem que,

[...] o desenvolvimento local apresenta-se como um princípio fundamental a consolidação das ideias de operacionalizar de forma responsável, de proteção às áreas naturais e ao mesmo tempo possibilitando tanto aos turistas, quanto aos visitados, experiências de vivência, respeitando as tradições e valores locais; oportunidades de envolvimento direto na operação do turismo, além de participação nas decisões, empoderando as comunidades envolvidas (CRUZ; MENDES; CAMPOS, 2017, p. 740).

Deste modo, o desenvolvimento local e o ecoturismo, desenham-se como um campo fértil para garantir a harmonização e convencionar compromissos quanto ao avanço da operação e reflexão sobre as condições adequadas de planejar o Ecoturismo, "[...] principalmente, quando apresenta alguns critérios como; o respeito às tradições e valores locais; oportunidades 
de amplo envolvimento local nos arranjos produtivos do turismo" e, neste caso, no APL de Turismo de Itacaré, Bahia (CRUZ; MENDES; CAMPOS, 2017, p. 741).

\section{Indicadores de Sustentabilidade: como medir o desenvolvimento sustentável?}

Os Indicadores de Desenvolvimento Sustentável (IDS) podem ser interpretados como um sistema de sinais que facilitam avaliar o progresso de países e regiões em direção ao desenvolvimento sustentável. De acordo com a Comisión Económica para América Latina y el Caribe (CEPAL, 2001), no documento intitulado Indicadores de sostenibilidad ambiental $y$ de desarrollo sostenible: estado del arte y perspectivas aponta que nos últimos anos, assiste-se a um desenvolvimento profuso no âmbito dos indicadores para a tomada de decisões, especialmente por parte dos países desenvolvidos, agências internacionais e, também, em alguns países latinoamericanos.

Ainda de acordo com a CEPAL (2001), enquanto alguns países desenvolvem indicadores de sustentabilidade ambiental, outros desenvolvem indicadores de desenvolvimento sustentável, incorporando as dimensões econômica, social, ambiental e institucional do desenvolvimento.

Nesse contexto, conforme IBGE (2000), o Brasil tem participado deste esforço, por meio de órgãos públicos, universidades, centros de pesquisas, instituições privadas e organizações não governamentais, e também de diversas iniciativas internacionais. Desta forma, para ajudar a tornar a sociedade mais sustentável, faz-se necessário desenvolver ferramentas que podem tanto medir, avaliar e facilitar progressos em direção a uma ampla gama de objetivos econômicos, sociais e ambientais (REED; FRASER; DOUGILL, 2006). Portanto, o envolvimento de todos os atores neste esforço de criar, aperfeiçoar e, invariavelmente, aplicar esses sistemas na direção ao desenvolvimento sustentável, aumentará sobremaneira a possibilidade de se obter êxito neste desafio.

De acordo com Reed, Fraser e Dougill (2006, p. 406) "a seleção e interpretação de 'indicadores de sustentabilidade' tornou-se parte integrante da política nacional e internacional nos últimos anos". Portanto, devem-se ter alguns cuidados na seleção e indicação dessas ferramentas e, em especial, no desenvolvimento de novos sistemas e indicadores de sustentabilidade. De acordo com IBGE (2000), considerar a integração das mensurações físicas e socioeconômicas, embora seja evidente a dificuldade de integrar ambos os aspectos, torna-se indispensável, quando se pretende atingir todas as dimensões da sustentabilidade: econômica, social e ambiental.

Nesse sentido, a definição de um conjunto de indicadores apropriados não é uma tarefa fácil, pois exige um trabalho que tem por objetivo compreender e selecionar indicadores relevantes, de acordo com as características do local onde será aplicado. Desta forma, Hanai e Espíndola (2012) observam que a conformidade dos indicadores se altera de acordo com as localidades e seu contexto. Devendo ser aplicados e interpretados 
dentro do contexto pertinente, considerando-se as características econômicas, sociais, geográficas, ecológicas e institucionais de cada localidade. Esses autores apontam, que entre as características desejáveis e mais importantes dos indicadores destacam-se:

\begin{abstract}
Confiáveis; de baixo custo de coleta e análise; simples; limitados em números; significativos; relevantes; eficientes; reativos; pertinentes; fáceis de entender; exequíveis; práticos; aceitos politicamente; mensuráveis; e controláveis pela gestão; precisos; exatos; consistentes; sensíveis a alterações do ambiente; conceitualmente bem fundamentados; dependentes apenas dos dados prontamente disponíveis; hábeis para mostrar tendências ao longo tempo (em longo prazo); e comparáveis ao longo do tempo e entre jurisdições e regiões (HANAl; ESPÍNDOLA, 2012, p. 299).
\end{abstract}

Assim, a identificação e a utilização desses indicadores se constituem em etapas importantes para a análise e avaliação da sustentabilidade das atividades econômicas. Nesse sentido, identificar e analisar as mudanças sociais e territoriais decorrentes dos impactos econômicos, sociais e ambientais, causados pela dinâmica dos APLs, requer a utilização de sistemas ou ferramentas que avaliam a aglomeração produtiva e a sua sustentabilidade. Para tanto, Bruna et al. (2012, p. 333) argumentam que "para se avaliar esses arranjos produtivos é preciso definir um conjunto de indicadores que relacionem os impactos negativos e os benéficos sentidos no uso e na ocupação do solo urbano". Desta forma, faz-se necessário relacionar e avaliar a concentração geográfica das atividades produtivas com a sustentabilidade do meio ambiente, considerando os aspectos regionais e locais relativos ao desenvolvimento sustentável.

Vale salientar, que bons indicadores exigem uma ou mais unidades de medida, tais como: tempo, área, peso, distância, entre outras; e muitas vezes padrões, sendo este, valores que expressam os limites nos quais a ocorrência de um indicador deve ser ou não nociva ao homem ou ao meio ambiente. Sendo assim, no âmbito deste trabalho, devem-se distinguir alguns conceitos, especificados no Quadro 1 (próxima página).

Consideram-se, para esta pesquisa algumas propriedades dos principais indicadores de sustentabilidade, especificamente, segundo Van Bellen (2006), os indicadores mais importantes e, portanto, necessários, são aqueles que simplifiquem as informações significativas, fazendo com que determinados fenômenos que acontecem na realidade se tornem mais evidentes, aspecto que é particularmente importante na problemática ambiental. Sendo que, as principais funções dos indicadores podem ser resumidas da seguinte forma: (i) Avaliação de condições e tendências; (ii) Comparações entre lugares e situações; (iii) Avaliação de condições e tendências em relação às metas e aos objetivos; (iv) Prover informações de 
advertência; e (v) Antecipar futuras condições e tendências (TUNSTALL apud VAN BELLEN, 2006).

Quadro 1: Produção de informação a partir de dados.

Table 2: Production of information from data.

\begin{tabular}{|c|c|}
\hline Tipo & Características \\
\hline Dados & $\begin{array}{l}\text { Informação no seu estado bruto, ou seja, não tratada. Componente } \\
\text { básico no trabalho com indicadores. }\end{array}$ \\
\hline Parâmetros & $\begin{array}{l}\text { Medidas de grandezas, que podem ser medidas com precisão ou } \\
\text { avaliadas qualitativa ou quantitativamente; imprescindível na } \\
\text { avaliação dos sistemas ambientais, econômicos, sociais e } \\
\text { institucionais. }\end{array}$ \\
\hline Padrão & $\begin{array}{l}\text { No contexto dos indicadores, os conceitos de padrão e norma são } \\
\text { similares. Eles se referem fundamentalmente a valores estabelecidos } \\
\text { ou desejados que expressem os limites nos quais a ocorrência de um } \\
\text { indicador deve ser ou não nociva ao homem ou ao meio ambiente. }\end{array}$ \\
\hline Indicadores & $\begin{array}{l}\text { Ferramenta analítica para o estudo de mudanças na sociedade. } \\
\text { Parâmetros que, isolados ou combinados, vão permitir os exercícios } \\
\text { de estatística e de especialização, com vista à análise e produção de } \\
\text { informação nova. Não são forçosamente valores e/ou números; } \\
\text { podem assumir diferentes formas como, por exemplo, sinais, } \\
\text { símbolos, imagens, cores; elementos não numéricos ou } \\
\text { quantificáveis, mas, sobretudo, qualificativos e, por isso, de enorme } \\
\text { importância. }\end{array}$ \\
\hline Índices & $\begin{array}{l}\text { A combinação de indicadores forma índices. Resultam da agregação } \\
\text { dos indicadores, segundo vários métodos, usados com mais } \\
\text { frequência em níveis de análise mais agregada, especialmente, nos } \\
\text { âmbitos regionais e nacionais. }\end{array}$ \\
\hline
\end{tabular}

Fonte: Van Bellen (2006); Malheiros, Coutinho e Philippi Jr. (2012), adaptado pelo autor. Source: Van Bellen (2006); Malheiros, Coutinho and Philippi Jr. (2012), prepared by the author.

Autores como Van Bellen (2006); Hanai e Espíndola (2012); Malheiros, Coutinho e Philippi Jr. (2012) concebem que são vários os modelos de indicadores e sistemas de sustentabilidade elaborados para mensurar os impactos da atividade humana, especialmente, centrados na atividade econômica. As atividades econômicas que se relacionam diretamente com o meio ambiente, também podem ser beneficiadas com 0 desenvolvimento de novos indicadores que considerem as especificidades de cada setor.

Como já mencionado anteriormente, alguns autores corroboram com a percepção que existe uma razoável convergência no sentido da necessidade de desenvolvimento de metodologias que façam uma avaliação da sustentabilidade. Entretanto, também, observa-se a ausência na literatura especializada de sistemas ou ferramentas que mensurem, simultaneamente, a aglomeração produtiva e a sustentabilidade das atividades econômicas. Permitindo, desta forma, identificar, mensurar e avaliar o desenvolvimento sustentável dessas atividades (VAN BELLEN, 2006).

Portanto, apresenta-se o Quadro 2 elencando os principais instrumentos de análise da sustentabilidade utilizados mundialmente. 
Quadro 2: Principais instrumentos de elaboração de IDS.

Table 2: Main tools for the development of IDS.

\begin{tabular}{|c|c|}
\hline Indicadores agregados e índices & Características \\
\hline $\begin{array}{c}\text { Pegada Ecológica } \\
\text { (Ecological Footprint Method) }\end{array}$ & $\begin{array}{l}\text { Indicador de sustentabilidade baseado em critérios } \\
\text { ecológicos, desenvolvido e proposto por Wackernagel } \\
\text { e Rees em 1996. Proposta: estimar a área requerida } \\
\text { para sustentar direta e indiretamente a atividade de } \\
\text { uma população ou de um sistema econômico. }\end{array}$ \\
\hline $\begin{array}{c}\text { Painel de Sustentabilidade } \\
\text { (Dashboard of Sustainability - } \\
\text { IISD) }\end{array}$ & $\begin{array}{l}\text { Índice agregado de vários indicadores que emprega } \\
\text { meios visuais de apresentação para apontar as } \\
\text { dimensões primárias da sustentabilidade. Fornece } \\
\text { informações quantitativas e qualitativas sobre o } \\
\text { progresso em direção à sustentabilidade. }\end{array}$ \\
\hline $\begin{array}{c}\text { Barômetro da Sustentabilidade } \\
\text { (Barometer of Sustainability - } \\
\text { IUCN) }\end{array}$ & $\begin{array}{l}\text { Ferramenta para medir e informar o bem-estar de uma } \\
\text { sociedade e o avanço em direção ao desenvolvimento } \\
\text { sustentável através da integração de indicadores } \\
\text { biofísicos e de saúde social. }\end{array}$ \\
\hline $\begin{array}{c}\text { Índice de Desenvolvimento } \\
\text { Humano (IDH) } \\
\text { (Human Development Index - } \\
\text { UN) }\end{array}$ & $\begin{array}{l}\text { Índice que mede as dimensões sociais e econômicas } \\
\text { do desenvolvimento, com base nos parâmetros da } \\
\text { expectativa de vida, educação e a renda per capita. } \\
\text { Foi desenvolvido pelas Nações Unidas nos anos } 1990 .\end{array}$ \\
\hline $\begin{array}{c}\text { Pressão-Estado-Resposta } \\
\text { (PER) } \\
\text { (Pressure, State, Response - } \\
\text { OECD) }\end{array}$ & $\begin{array}{l}\text { Sistema de indicadores de sustentabilidade } \\
\text { amplamente usado e conhecido internacionalmente. } \\
\text { Proposto por um grupo de pesquisadores canadenses } \\
\text { no início dos anos } 1990 \text {. Este modelo foi adotado pela } \\
\text { Organization for Economic and Cooperation } \\
\text { Development (OECD). }\end{array}$ \\
\hline
\end{tabular}

Fonte: Van Bellen (2006); Malheiros, Coutinho e Philippi Jr. (2012); Moreira (2013), adaptado pelo autor.

Source: Van Bellen (2006); Malheiros, Coutinho and Philippi Jr. (2012); Moreira (2013), prepared by the author.

Há muitos métodos e indicadores aplicados na análise de concentração, localização e especialização das atividades econômicas regionais ou locais, neste estudo, utiliza-se o Quociente Locacional (QL) como procedimento metodológico para a análise dos APLs. Neste contexto, a seguir apresenta-se o método de identificação e classificação de aglomerações produtivas em regiões de baixo e médio desenvolvimento.

\section{Procedimentos metodológicos}

Neste trabalho são apresentadas as características do APL, principalmente, nos aspectos de sustentabilidade ambiental. O levantamento de dados primários desta pesquisa foi direcionado às empresas de turismo, referentes aos meios de hospedagem, em Itacaré, Bahia. O procedimento amostral adotado foi amostragem não probabilística, utilizando-se como critério o de acessibilidade, também chamada por conveniência. Segundo Dencker (1998), Vergara (2003) e Gil (2010), na amostragem não probabilística por acessibilidade a facilidade de acesso deve ser representativa do universo pesquisado. 
Foram realizadas 30 entrevistas junto aos gestores das empresas que atuam no setor de hospedagem que integram o setor de turismo, no período de 13 a 21 de junho de 2016. O conjunto de informações levantadas foi utilizado para caracterizar e analisar o APL de Turismo¹.

Os questionários utilizados foram adaptados da Redesist para suportar análise de fatores intangíveis, tais como: cooperação, inovação e interação e, também, contou com adaptações provenientes do Sistema de Classificação dos Meios de Hospedagem do Ministério do Turismo (Mtur), a fim de validar a análise da sustentabilidade ambiental. Estes instrumentos foram testados à realidade empírica, e logo após aplicados no levantamento dos dados e informações pretendidas.

Em Itacaré, as entrevistas possibilitaram captar informações qualitativas e quantitativas sobre as fontes de informação para o aprendizado, grau de integração, nível de cooperação, inovações entre outras, e dessa forma caracterizar as instituições de apoio, o número de empresas, o perfil dos empreendedores e os problemas enfrentados pelo setor na localidade.

No que diz respeito à metodologia, o trabalho privilegia dois recortes metodológicos: (i) um recorte quantitativo, utilizado para a identificação de aglomerações produtivas, o Quociente Locacional (QL), e; (ii) um recorte analítico, utilizado para a caracterização de aglomerações produtivas em regiões de baixo e médio desenvolvimento, denominado Arranjo Produtivo Local (APL) (LASTRES; CASSIOLATO, 2003).

Através desta metodologia é possível captar a conformação de arranjos produtivos locais, e associada a pesquisa qualitativa, utilizada para analisar fatores intangíveis, pode-se classificar os APLs quanto à complexidade e ao grau de maturidade, conforme classificação tipificada pelo MCT, já especificada anteriormente.

Um APL de turismo se caracteriza pela existência de uma atividadenúcleo, especificamente ancorada no setor da hospitalidade (hotéis, pousadas, resorts, entre outros) e, também, por uma série de outras atividades integradas, responsáveis pelo fornecimento de insumos, produtos, equipamentos e serviços de apoio para a realização ou para a manutenção da atividade central (BRITO, 2002).

A base de dados refere-se apenas ao mercado formal de trabalho deixando de captar informações sobre atividades exercidas informalmente, mas que fazem parte da atividade aqui analisada. Foram, portanto, utilizados os dados da Relação Anual de Informações Sociais (RAIS), por meio da Classificação Nacional de Atividades Econômicas (CNAE) relativos ao ano de 2015, que traz informações sobre o número de empresas, pessoal ocupado e salários pagos pelas empresas de turismo, notadamente representadas pelos meios de hospedagem, neste caso específico os hotéis e pousadas, combinados ou não com o serviço de alimentação (CNAE 55108/01). Adotando-se como base o total de empregados registrados (EMP) nos municípios informados pela RAIS, o cálculo do QL aplicado à atividade turística foi calculado da seguinte forma, conforme Haddad (1989), Brito 
(2002), De Sordi e Meireles (2012):

$\mathrm{QL}=(\mathrm{EMP}$ setor i/EMP município j) / (total do país EMP setor i/ total do país EMP)

Em que:

$\mathrm{QL}=$ Quociente locacional;

EMP setor $\mathbf{i}=$ empregados do setor de turismo no município;

EMP município $\mathbf{j}=$ total de empregados no município;

Total do país EMP setor $\mathbf{i}=$ total de empregados do setor de turismo no

Brasil;

Total do país EMP = total de empregados no Brasil.

O Quociente Locacional compara o peso relativo de uma determinada atividade em um determinado município ou localidade com o peso relativo daquela atividade no nível nacional. Quando o Quociente Locacional for maior que a unidade $(\mathrm{QL}>1)$ revela que o município ou localidade contribui mais proporcionalmente que a média nacional para a atividade em questão, ou seja, a especialização do município $\mathbf{j}$ em atividades do setor $\mathbf{i}$ é superior à especialização do conjunto do Brasil nas atividades desse setor. Caso contrário, quando o Quociente Locacional for igual à unidade $(\mathrm{QL}=1)$, a especialização do município $\mathbf{j}$ em atividades do setor $\mathbf{i}$ é idêntica à especialização do conjunto do Brasil nas atividades desse setor e, quando o Quociente Locacional for menor que a unidade $(Q L<1)$, a especialização do município $\mathbf{j}$ em atividades do setor $\mathbf{i}$ é inferior à especialização do conjunto do Brasil nas atividades desse setor (BRITO, 2002).

\section{Resultados e Discussão}

Nesta seção são apresentados os resultados da pesquisa acerca da identificação e caracterização das aglomerações produtivas em regiões de baixo e médio desenvolvimento. Os resultados encontrados que conformam a atividade do turismo na localidade selecionada para a pesquisa, foi baseado no Coeficiente de Especialização deste destino turístico do sul da Bahia.

A fim de subsidiar a análise, procurou-se utilizar uma metodologia para a caracterização do Arranjo Produtivo Local. Para tanto, foi selecionado - Arranjo Produtivo Local do Turismo de Itacaré, que representa um dos destinos turísticos mais demandados no sul da Bahia. Adotando-se como base o total de empregados registrados (EMP) no município selecionado, informado pela RAIS, e utilizando-se o cálculo do Quociente Locacional (QL), encontra-se, para a classe CNAE № 5510-8 (Hotéis e similares) que compõem a atividade-núcleo do APL de turismo, o resultado do Quociente Locacional deste destino turístico (Tabela 1).

Neste caso, a Tabela 1 registrou o Coeficiente de Especialização referente aos meios de hospedagem do município pesquisado, em 2015, apontando forte concentração espacial desta atividade na cadeia produtiva do turismo, nesta localidade. 
Tabela 1: Coeficiente de especialização do APL de Turismo de Itacaré, Bahia.

Table 1: Coefficient of specialization of Tourism APL of Itacaré, Bahia.

\section{Atividade: Hotéis e similares - CNAE 5510-8}

Município

Itacaré

Código

Empregos/2015

\section{QL}

Fonte: RAIS/2015 (BRASIL, 2017), adaptado pelo autor.

Source: RAIS/2015 (BRASIL, 2017), prepared by the author.

\section{APL de Turismo de Itacaré, BA, Brasil}

O destino turístico de Itacaré, BA, está localizado na Costa do Cacau, compondo com a Costa do Dendê a região turística denominada pelo Mtur de Polo Litoral Sul. Está, portanto, inserido no sul da Bahia. A Costa do Cacau é formada pelos seguintes municípios: Canavieiras, Ilhéus, Itabuna, Itacaré, Pau Brasil, Santa Luzia, Una e Uruçuca. Já a Costa do Dendê: Cairu, Camamu, Igrapiúna, Ituberá, Maraú, Nilo Peçanha, Presidente Tancredo Neves, Teperoá e Valença (Figura 1).

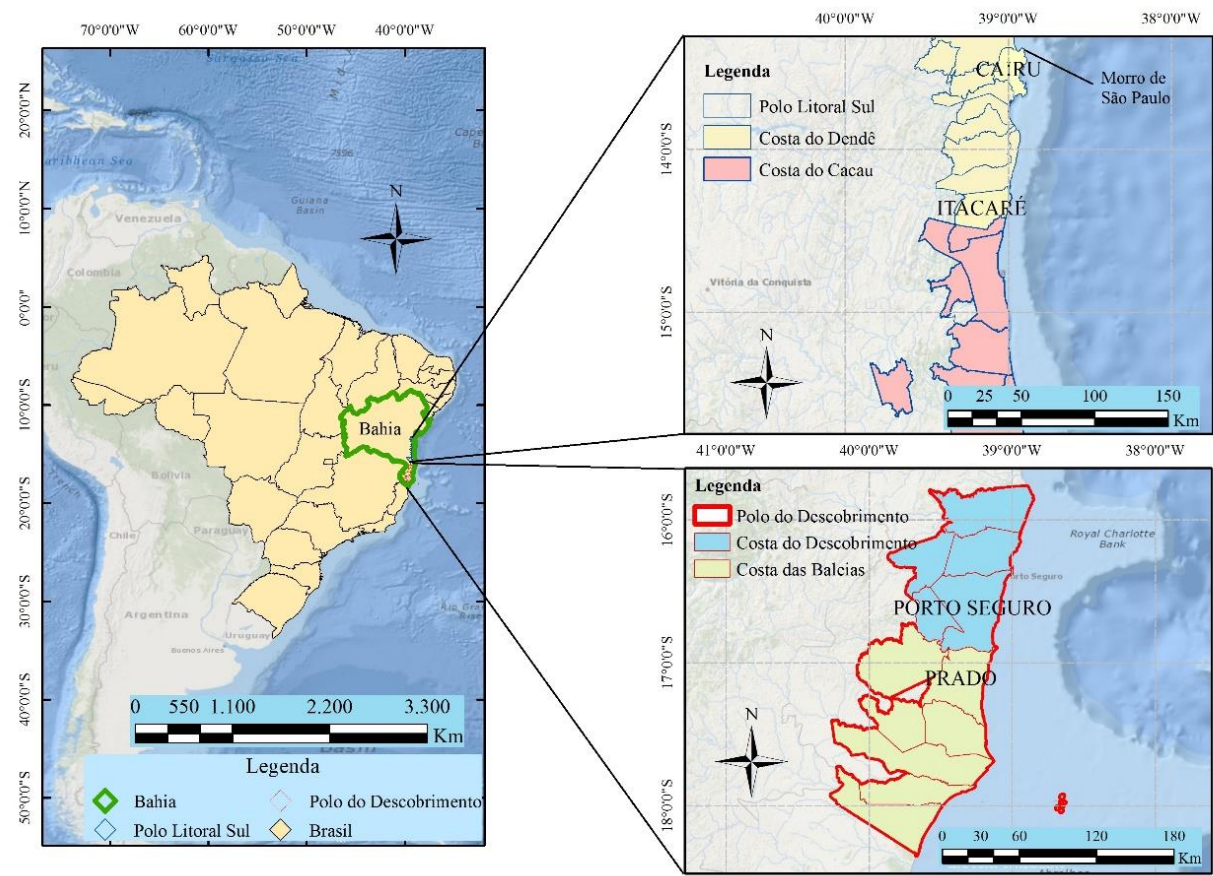

Figura 1: Mapa de localização do município de Itacaré, Bahia Figure 1: Map of location of the municipality of Itacaré, Bahia.

Fonte: Elaborado pelo autor).

Source: Prepared by the author.

De acordo com o IBGE (2017), Itacaré é o município da Bahia com área da unidade territorial de 726,167 $\left(\mathrm{km}^{2}\right)$, localizado ao Sul da capital Salvador a $14^{\circ} 18^{\prime}$ de latitude Sul e $39^{\circ} 02^{\prime}$ de longitude Oeste do Meridiano de Greenwich, a uma distância de 532 km via BR-101 e BR-324 e, ao Norte de llhéus, a uma distância de $65 \mathrm{~km}$ via BA-001.

No Censo de 2010, o município do Itacaré, BA, possuía 24.318 habitantes, com densidade demográfica em 2010 de 32,96 (hab/ $\left./ \mathrm{km}^{2}\right)$. $\mathrm{O}$ IBGE (2017) estima para 2016 uma população de 28.013, indicando um crescimento populacional de $15,2 \%$. A cidade de llhéus é o portão de acesso 
aéreo, marítimo e rodoviário. O clima do Município é tropical com chuvas frequentes durante o inverno (maio a agosto) e as temperaturas médias diárias variam entre $25^{\circ} \mathrm{C}$ e $30^{\circ} \mathrm{C}$, podendo chegar aos $40^{\circ} \mathrm{C}$ no verão temporada (dezembro, janeiro e fevereiro).

O desempenho econômico e social deste município, no período de 1991 a 2010, pode ser observado pelo Índice de Desenvolvimento Humano Municipal (IDH-M). O município cresceu 141,91\%, passando de 0,241 em 1991 para 0,583 em 2010. Neste período a distância do IDH do município e o limite máximo do IDH, ou seja, 1 - IDH foi reduzido em 44,74\%. A dimensão que mais contribuiu para este crescimento foi a longevidade com 0,807, seguida pela renda, com 0,594 e pela educação, com 0,413 (PNUD, 2013). O ranking do IDHM 2010 do Programa das Nações Unidas para o Desenvolvimento (PNUD), classifica o município de Itacaré na 4562을 posição, entre 5565 Municípios ranqueados.

O município de Itacaré é um dos 218 maiores destinos turísticos, considerados indutores do desenvolvimento do turismo no Brasil, representando 4,99\% (Categoria B com 167 municípios) dos destinos turísticos mais demandados do país, de um total de 3.345 municípios categorizados pelo MTur e inseridos no Mapa do Turismo Brasileiro (BRASIL, 2015).

No município de Itacaré, encontram-se os principais equipamentos e serviços turísticos que fazem parte das atividades característica do setor, tais como: transporte, meios de hospedagem, equipamentos de alimentação e bebidas fora da residência, locadoras de automóveis, agências de viagem receptivo e espaços de lazer e cultura.

No Ecoturismo praticado neste destino, a oferta turística, além desses equipamentos e serviços, inclui também atividades na natureza que permitem a integração do turista com o ambiente natural. Algumas das atividades que podem ser realizadas no âmbito deste segmento são: observação de fauna; observação de flora; observação de formações geológicas e as visitas a cavernas (espeleoturismo); observação astronômica; e, em especial nesta região, mergulho livre; caminhadas; trilhas e safáris fotográficos (BRASIL, 2010).

A superestrutura turística existente em Itacaré conta com oferta de 96 meios de hospedagem, entre quatro hotéis, 84 pousadas, seis hostels e duas hospedagens rurais, que disponibilizam 1.532 unidades habitacionais (UHs) e 4.511 leitos. Destaca-se, também, a presença de 174 empreendimentos de alimentos e bebidas (A\&B), que transformam este destino turístico em centro gastronômico da Costa do Cacau, justificando o aumento da atividade turística ocorrido nos últimos anos.

Como já abordado anteriormente, a cadeia produtiva do turismo que estas empresas se encontram é formada por uma diversidade de segmentos turísticos, e estão centradas, especialmente, nas atividades que representam a hospitalidade, inseridas no setor terciário da economia local.

Na investigação realizada, além de considerar o QL calculado para o município de Itacaré $(\mathbf{Q L}=\mathbf{2 4 , 1 4})$, procurou-se, também, considerar uma 
participação mínima do município no emprego e remunerações da classe CNAE no total do país. Neste estudo foi utilizado para caracterizar a relevância de cada aglomeração, o limite de $0,1 \%$ do emprego total no ramo de atividade. Segundo Brito (2002), necessário se faz acrescentar à análise algum critério de densidade mínima, em referência ao número de estabelecimentos na delimitação do APL selecionado. Neste estudo, optouse por um critério mínimo de densidade especialmente abrangente, condicionado a um mínimo de 3 (três) estabelecimentos em funcionamentos nos municípios na atividade (classe CNAE) considerada.

Utilizando-se a metodologia abordada, com base na relação CNAES foi identificado no Arranjo Produtivo Local de Turismo de Itacaré um total de 137 estabelecimentos, com base nos dados da RAIS, responsáveis pela geração de 779 empregos formais no ano de 2015, conforme demonstrado na Tabela 2. A Tabela indica que a participação das atividades ligadas diretamente às atividades-núcleo do APL (Hotéis e Similares), no total de emprego e da remuneração do município em Itacaré é significativa, correspondendo a $25,8 \%$ dos empregos gerados e a $21,6 \%$ das remunerações no município.

Tabela 2: Características do APL de Turismo de Itacaré e a participação na economia do município.

Table 2: Characteristics of the Tourism APL of Itacare and the participation in the economy of the municipality.

\begin{tabular}{|c|c|c|c|c|c|c|c|c|}
\hline APL de Turismo & \begin{tabular}{|l|}
$\begin{array}{c}\text { Empre- } \\
\text { gados }\end{array}$ \\
\end{tabular} & $\begin{array}{l}\% \text { no } \\
\text { Munic. }\end{array}$ & $\begin{array}{c}\text { № } \\
\text { Estab. }\end{array}$ & $\begin{array}{l}\% \text { no } \\
\text { Munic. }\end{array}$ & $\begin{array}{c}\text { Remu- } \\
\text { neração }\end{array}$ & $\begin{array}{l}\% \text { no } \\
\text { Munic. }\end{array}$ & $\begin{array}{l}\text { Porte } \\
\text { médio }\end{array}$ & $\begin{array}{l}\text { Rem. } \\
\text { Média }\end{array}$ \\
\hline $\begin{array}{l}\text { Atividades-núcleo } \\
\text { do APL }\end{array}$ & 502 & 16,7 & 48 & 9,2 & $592.504,81$ & 14,6 & 10,5 & $1.180,29$ \\
\hline $\begin{array}{l}55.10-8 \text { Hotéis e } \\
\text { similares }\end{array}$ & 502 & 16,7 & 48 & 9,2 & $592.504,81$ & 14,6 & 10,5 & $1.180,29$ \\
\hline $\begin{array}{l}\text { Atividade integra- } \\
\text { da: Serviços de } \\
\text { alimentação }\end{array}$ & 238 & 7,9 & 76 & 14,6 & $236.647,22$ & 5,8 & 3,1 & 994,32 \\
\hline $\begin{array}{l}56.11-2 \\
\text { Restaurantes e } \\
\text { similares }\end{array}$ & 238 & 7,9 & 76 & 14,6 & $236.647,22$ & 5,8 & 3,1 & 994,32 \\
\hline $\begin{array}{l}\text { Atividade Integra- } \\
\text { da: Agências e } \\
\text { organizadoras de } \\
\text { viagens }\end{array}$ & 35 & 1,2 & 10 & 1,9 & $42.326,14$ & 1,0 & 3,5 & $1.209,32$ \\
\hline $\begin{array}{l}79.11-2 \text { Agências } \\
\text { de viagens }\end{array}$ & 35 & 1,2 & 10 & 1,9 & $42.326,14$ & 1,0 & 3,5 & $1.209,32$ \\
\hline $\begin{array}{l}\text { Atividade integra- } \\
\text { da: Atividades } \\
\text { desportivas e } \\
\text { recreativas }\end{array}$ & 4 & 0,1 & 3 & 0,6 & $4.984,30$ & 0,12 & 1,3 & $1.246,08$ \\
\hline $\begin{array}{l}93.29-8 \\
\text { Discotecas, dance- } \\
\text { terias, salões de } \\
\text { dança e similares }\end{array}$ & 4 & 0,1 & 3 & 0,6 & $4.984,30$ & 0,12 & 1,3 & $1.246,08$ \\
\hline $\begin{array}{l}\text { Turismo e } \\
\text { atividades } \\
\text { associadas }\end{array}$ & 779 & 25,8 & 137 & 26,3 & $876.462,47 \mid$ & 21,6 & 5,7 & $1.125,11$ \\
\hline
\end{tabular}

Fonte: OMT (2008); RAIS/2015 (BRASIL, 2017), adaptado pelo autor.

Source: OMT (2008); RAIS/2015 (BRASIL, 2017), prepared by the author. 
Em termos do tamanho médio de estabelecimento, o município caracteriza-se por uma concentração de microempresas, encontrando-se a média de 5,7 empregados por empresas relacionadas. Cabe ressaltar também que, dos 4 (quatro) segmentos identificados com base na metodologia descrita, a remuneração média paga aos empregados foi de $R \$$ $1.125,11$.

Constata-se moderado adensamento das atividades que conformam a cadeia produtiva do turismo de Itacaré. Com base na metodologia adotada, verifica-se a ausência e/ou número reduzido de estabelecimentos representativos das atividades que estão normalmente conectadas a cadeia principal do turismo (hotéis, pousadas, bares, restaurantes e afins), especialmente: transportes, aluguel de equipamentos de transportes, atividades culturais, desportivas e recreativas, entre outras.

Para a análise de fatores intangíveis tais como cooperação, inovação e interação, a pesquisa contou com a aplicação de questionário adaptado da Redesist, do Instituto de Economia da Universidade Federal do Rio de Janeiro (UFRJ), para Arranjos Produtivos Locais (LASTRES; CASSIOLATO, 2003). No caso do APL de Turismo de Itacaré, o universo (população) da pesquisa de campo foi delimitado às empresas de turismo, notadamente representadas pelos meios de hospedagens. Deste modo, foi definida uma amostra não probabilística, utilizando-se o critério de acessibilidade, também chamada por conveniência. Foram entrevistados e solicitados a responder 0 referido questionário 30 empreendedores, diretores e gerentes das empresas que compuseram a amostra. As entrevistas e respostas dos questionários auxiliaram na caracterização e análise do arranjo.

As entrevistas realizadas forneceram informações qualitativas e quantitativas sobre práticas comerciais, grau de integração, capacitação tecnológica, nível de cooperação entre outras. Estas entrevistas proporcionaram uma visão detalhada do relacionamento com as instituições de apoio, número de empresas, problemas enfrentados pelo setor do turismo da Costa do Cacau e, neste estudo, em especial, de Itacaré, BA.

Em relação à sustentabilidade, estas entrevistas fornecem, também, informações baseadas nos critérios estabelecidos na Matriz de Classificação de Meios de Hospedagem do Mtur (BRASIL, 2011), destacando-se quesitos de sustentabilidade como a redução do consumo de energia elétrica e água, gerenciamento de resíduos sólidos, medidas permanentes para valorizar a cultura local, medidas permanentes de apoio as atividades socioculturais, geração de trabalho e renda para a comunidade local e promoção da produção associada ao turismo.

Os meios de hospedagem que compuseram a amostra, no total de 30 equipamentos (Resorts, hotéis e pousadas) representam $31 \%$ da oferta total de Itacaré. Destaca-se que os empreendimentos pesquisados estão circunscritos no perímetro urbano da sede do município. O conjunto de equipamentos em análise, disponibiliza 577 quartos e 1.590 leitos, representando $38 \%$ e $35 \%$, respectivamente, da oferta deste destino turístico. 
Constata-se, que no Arranjo Produtivo Local do Turismo de Itacaré, predomina a participação de microempresas $(86,7 \%$ do total dos participantes da pesquisa), sendo o restante de pequenos empreendimentos $(10 \%)$ e apenas $3,3 \%$ de médias empresas. Constatou-se, também, a ausência de grandes empresas atuando no município. Outro aspecto diz respeito a constituição do capital desses empreendimentos turísticos, formados integralmente com capital nacional.

Quanto aos empregos gerados por estas empresas, verificou-se que a liderança na geração desses postos de trabalhos concentra-se nas microempresas do arranjo (44,7\%). As pequenas empresas são responsáveis pela oferta de $29,5 \%$ dos empregos do setor. Ficando a geração de $25,8 \%$ dos empregos dos meios de hospedagem por conta das médias empresas de Itacaré. Configura-se, dessa forma, que o potencial de oferta de postos de trabalho está concentrado nas micro e pequenas empresas, que respondem por $74,2 \%$ dos empregos ofertados pelas empresas pesquisadas.

No aspecto mercadológico, as empresas do arranjo apontaram a configuração da demanda exercida neste destino turístico. Neste contexto, verificou-se a baixa participação do turismo internacional em 2015, na ocupação das pousadas e hotéis. Dados que corroboram com esta situação são expressos por: (i) na microempresa a relação de turistas nacionais e estrangeiros, situam-se na ordem de $83,2 \%$ e $16,8 \%$, respectivamente; (ii) na pequena empresa esses números situam-se em $92,7 \%$ e $7,3 \%$; e (iii) na média empresa do arranjo produtivo de Itacaré, essa relação sobe consideravelmente, ficando registrados em $65,0 \%$ para o turismo nacional e $35,0 \%$ para o turismo internacional.

A fim de se obter maior inserção no mercado internacional e, ao mesmo tempo, ampliar a participação de mercado no turismo doméstico, a competitividade assume papel central nas estratégias de consolidação do arranjo. Para tanto, com o objetivo de descrever as características da estrutura produtiva do APL do Turismo de Itacaré, a pesquisa procurou identificar quais os fatores são determinantes para a manutenção e, sendo possível, ampliação da capacidade produtiva na atividade exercida pelos meios de hospedagem pesquisados. No questionário aplicado aos gestores das empresas, os fatores competitivos foram classificados de acordo com 0 grau de importância atribuído por cada empresa.

Para Porter (1998), não há consenso para se definir o conceito de competitividade. Entretanto, para as empresas, significa a habilidade em competir em marcados globalizados, utilizando-se de estratégias definidas. As estratégias podem se apoiar em vantagem absoluta de custo, diferenciação de produto ou economia de escala.

De acordo com as empresas visitadas, há praticamente unanimidade quanto à elevada importância dos seguintes fatores determinantes para a competitividade das empresas, instaladas em Itacaré, conforme Tabela 3 , destacando-se: (i) qualidade da mão de obra; (ii) estratégia de comercialização; (iii) qualidade do produto; e (iv) capacidade de atendimento. 
Tabela 3: Fatores competitivos para as empresas do APL de Itacaré, BA (\%).

Table 3: Competitive factors for the APL companies of Itacaré, BA (\%).

\begin{tabular}{|c|c|c|c|c|c|c|c|c|c|c|c|c|}
\hline \multirow{2}{*}{ Fatores competitivos } & \multicolumn{4}{|c|}{ Micro } & \multicolumn{4}{|c|}{ Pequena } & \multicolumn{4}{|c|}{ Média } \\
\hline & Nula & Baixa & Média & Alta & Nula & Baixa & Média & Alta & Nula & Baixa & Média & Alta \\
\hline $\begin{array}{l}\text { 1. Qualidade da mão- } \\
\text { de-obra }\end{array}$ & 0,0 & 0,0 & 3,8 & 96,2 & 0,0 & 0,0 & 0,0 & 100,0 & 0,0 & 0,0 & 0,0 & 100,0 \\
\hline $\begin{array}{l}\text { 2. Custo da mão-de- } \\
\text { obra }\end{array}$ & 0,0 & 3,8 & 23,1 & 73,1 & 0,0 & 33,3 & 0,0 & 66,7 & 0,0 & 0,0 & 0,0 & 100,0 \\
\hline $\begin{array}{l}\text { 3. Nível tecnológico } \\
\text { dos equipamentos }\end{array}$ & 0,0 & 0,0 & 19,2 & 80,8 & 0,0 & 0,0 & 0,0 & 100,0 & 0,0 & 0,0 & 0,0 & 100,0 \\
\hline $\begin{array}{l}\text { 4. Capacidade de } \\
\text { introdução de novos } \\
\text { produtos/processos }\end{array}$ & 0,0 & 3,8 & 30,8 & 65,4 & 0,0 & 0,0 & 0,0 & 100,0 & 0,0 & 0,0 & 0,0 & 100,0 \\
\hline $\begin{array}{l}\text { 5. Estratégias de } \\
\text { comercialização }\end{array}$ & 0,0 & 0,0 & 3,8 & 96,2 & 0,0 & 0,0 & 0,0 & 100,0 & 0,0 & 0,0 & 0,0 & 100,0 \\
\hline $\begin{array}{l}\text { 6. Qualidade do } \\
\text { produto } \\
\text { 7. Canacidade de }\end{array}$ & 0,0 & 0,0 & 0,0 & 100,0 & 0,0 & 0,0 & 0,0 & 100,0 & 0,0 & 0,0 & 0,0 & 100,0 \\
\hline $\begin{array}{l}\text { 7. Capacıdade de } \\
\text { atendimento (volume } \\
\text { e prazo) }\end{array}$ & 0,0 & 3,8 & 3,8 & 92,3 & 0,0 & 0,0 & 0,0 & 100,0 & 0,0 & 0,0 & 0,0 & 100,0 \\
\hline
\end{tabular}

Fonte: Elaborado pelo autor (2017).

Source: Prepared by the author (2017).

O custo da mão de obra também se configurou como um fator de competitividade para as empresas do arranjo. Atribuindo-se ao custo desse fator uma considerável importância na formação do preço dos serviços oferecidos, principalmente, quando se leva em conta o nível de concorrência que se estabelece na região, em função da oferta expressiva de meios de hospedagem, quartos e leitos em Itacaré. As microempresas, pequenas e médias, participantes da pesquisa, apontaram a grande importância do fator mão de obra $73,1 \%, 66,7 \%$ e $100,0 \%$, respectivamente, como componente do custo e importante na competitividade do setor. Estratégia que pode ser definida como vantagem absoluta de custo.

O nível tecnológico dos equipamentos e a capacidade de introdução de novos produtos/serviços e processos convergiram nas indicações como elementos de considerável grau de importância como fatores de competitividade das empresas turísticas, em especial, das pousadas, hotéis e resorts que compuseram a amostra. As micro (80,8\%), pequenas (100,0\%) e médias $(100,0 \%)$ empresas consignaram como de alta importância o nível tecnológico dos equipamentos.

Estabelece-se nas empresas do arranjo a estratégia de diferenciação de produto, tanto pela atualização tecnológica dos equipamentos quanto na introdução e oferecimentos de produtos e serviços diferenciados. A introdução de novos produtos e/ou processos, também, foram apontados como fator de competitividade dos meios de hospedagem. Destacam-se alguns desses serviços oferecidos na região: café da manhã, chá da tarde, sistema all inclusive, academias de ginástica e musculação, serviços de spa, guarda-volumes, guia turístico, estacionamento, serviço de lavanderia, entre outros, que estão associados ao porte do empreendimento.

No contexto que se desenvolve a presente pesquisa, ganhou 
destaque a promoção de ações sobre arranjos produtivos locais, sendo necessárias ações orientadas para a constituição e o fortalecimento de arranjos produtivos que visem ao fortalecimento da cooperação e do aprendizado para a inovação. A articulação de projetos, que contribuam para aumentar a competitividade sistêmica dos APLs e das empresas que atuam em segmentos da cadeia produtiva do turismo, que possuem considerável potencial para o turismo internacional, são necessários para a aceleração e sustentabilidade do processo de desenvolvimento local.

Um dos caminhos para as empresas criarem vantagens competitivas são as inovações. Deste modo, cabe ressaltar a importância para as empresas turísticas, em especial, os meios de hospedagem, o desenvolvimento de novos procedimentos para comercializar, oferecendo novos produtos e serviços.

Constata-se que há busca pela inovação dentro do APL de turismo em Itacaré. As ações desenvolvidas pelas empresas, quanto à introdução de inovações, no período de 2013 a 2015, foram expressivas em relação às inovações de produto.

Essas informações endossam o entendimento que as inovações organizacionais apontam para um resultado melhor em relação às inovações de produtos e processos. Quanto as técnicas avançadas de gestão, todas as pequenas e médias empresas do setor disseram que implementaram essas técnicas e, por outro lado, $61,5 \%$ das microempresas não adotaram essas práticas organizacionais. Entretanto, as microempresas adotam outra postura no que diz respeito às mudanças nos conceitos e/ou práticas de marketing: 76,9\% das microempresas atribuíram alta importância a este quesito. Para as pequenas e médias empresas a inovação organizacional na área de marketing tem $100 \%$ de aprovação. Adiciona-se a estas práticas 0 aspecto da comercialização. As pequenas e médias empresas, responderam afirmativamente em relação à implantação desta inovação organizacional.

Verifica-se que o impacto resultante da introdução de inovações implementadas durante os últimos três anos, 2013 a 2015, nas empresas do APL de Turismo de Itacaré, conforme resultado da pesquisa, aponta para o aumento da produtividade das empresas do setor: (i) na microempresa os empreendedores e/ou gestores apontaram como média $(53,8 \%)$ e alta importância $(11,5 \%)$ o impacto das inovações no aumento da produtividade em suas empresas; (ii) na pequena empresa esse resultado foi apontado com $66,7 \%$ média e 33,3\% alta importância para as inovações estabelecidas em seus empreendimentos; e (iii) para a média empresa este fator contribuiu para o aumento da produtividade com expressivos $100,0 \%$ de alta importância.

Outros fatores revelaram-se significativos quando se verifica a importância do impacto gerado pelas inovações introduzidas nas empresas do arranjo. Destacam-se o aumento da qualidade dos produtos e serviços ofertados aos turistas, tanto no receptivo nacional quanto internacional. $\mathrm{Na}$ microempresa esse efeito foi considerado de média e alta importância por $32,0 \%$ e $52,0 \%$ respectivamente, com taxa de efetividade da ordem de $84,0 \%$. Já as pequenas e médias empresas atribuíram $100,0 \%$ de alta 
importância para esse impacto no incremento de inovações para 0 desempenho das empresas do setor.

Esses resultados permitiram, segundo os entrevistados, a manter a participação no mercado: $65,4 \%, 100,0 \%$ e $100,0 \%$ das microempresas, pequenas e médias empresas consideraram esses fatores de alta importância, respectivamente, para a manutenção do market share no APL de Turismo de Itacaré.

Certamente, as características da mão de obra local podem contribuir para o nível de competitividade e o padrão de inovação das empresas do arranjo. De uma maneira geral a avaliação feita pelas empresas pesquisadas relacionadas ao perfil de qualificação da mão de obra na região, retratam o desempenho do IDH-M deste município, especialmente, quando se verifica que a educação contribuiu com apenas 0,413 para a formação do IDH-M de 2010 (0,583). Portanto, a escolaridade da população, considerando apenas primeiro e segundo grau completos foi considerado de baixa, média e alta importância pelas microempresas com escores de $61,5 \%, 26,9 \%$ e $11,5 \%$, respectivamente. Para as pequenas empresas $100,0 \%$ de média importância e, as médias empresas atribuíram 100,0\% de alta importância para este item.

Quanto a escolaridade em nível superior e técnico, a avaliação feita pelas empresas pesquisadas guarda uma visão mais preocupante, apontando $100,0 \%$ de baixa importância para esta especificação, independentemente do porte das empresas. Outro fator que pode contribuir para a competitividade das empresas do arranjo, diz respeito ao conhecimento prático e/ou técnico na atividade hoteleira. Este item foi avaliado da seguinte forma: (i) microempresas: 46,2\% baixa, 46,2\% média e 7,6\% alta importância; (ii) pequenas empresas 100,0\% baixa importância; e (iii) médias empresas $100,0 \%$ baixa importância.

Pode-se atribuir a baixa avaliação da escolaridade superior e técnica na atividade a característica do setor na utilização de mão de obra semiespecializada, prevalecendo o conhecimento tácito como forma de aprendizado. Outras características, tais como: disciplina, flexibilidade, criatividade também foram avaliadas com relativa importância, e, também, a capacidade para aprender novas qualificações situa-se como de média e alta importância, conforme consignado na presente pesquisa.

Como já abordado, as economias de aglomeração vêm proporcionando às empresas participantes vantagens competitivas, possibilitando a sua existência e crescimento em um mundo cada vez mais competitivo. Os ganhos de produtividade que se verificam nas empresas e, em seu entorno, denomina-se economias externas ou de externalidades.

Neste contexto, podem-se relacionar algumas externalidades positivas encontradas nos aglomerados produtivos, tais como: a possibilidade oferecida por um grande mercado local de viabilizar a existência de fornecedores de insumos; uma oferta considerável de mão de obra especializada; a troca de informações que ocorre quando empresas do mesmo setor se aglomeram; a difusão do conhecimento tácito, entre outras. 
A Tabela 4 apresenta as externalidades locais que são observadas no APL do Turismo de Itacaré, de acordo com a visão das empresas entrevistadas. Na avaliação sobre as principais vantagens e desvantagens relacionadas com a localização das empresas no arranjo, não foi apontado nenhum fator, de forma unanime, que explicasse a escolha da localização da firma, nesta localidade. Prevaleceu os aspectos negativos, entre eles: (i) Proximidade com os fornecedores de insumos e matéria prima; (ii) Proximidade com os clientes/consumidores; e (iii) Infraestrutura física (energia, transporte, comunicações).

Tabela 4: Vantagens da localização no arranjo (\%).

Table 4: Advantages of location in the arrangement (\%).

\begin{tabular}{|c|c|c|c|c|c|c|c|c|c|c|c|c|}
\hline \multirow{2}{*}{ Externalidades } & \multicolumn{4}{|c|}{ Micro } & \multicolumn{4}{|c|}{ Pequena } & \multicolumn{4}{|c|}{ Média } \\
\hline & Nula & Baixa & Média & Alta & Nula & Baixa & Média & Alta & Nula & Baixa & Média & Alta \\
\hline $\begin{array}{l}\text { 1. Disponibilidade de } \\
\text { mão de obra } \\
\text { qualificada }\end{array}$ & 0,0 & 92,3 & 7,7 & 0,0 & 0,0 & 100,0 & 0,0 & 0,0 & 0,0 & 100,0 & 0,0 & 0,0 \\
\hline $\begin{array}{l}\text { 2. Baixo custo da mão } \\
\text { de obra }\end{array}$ & 0,0 & 53,8 & 34,6 & 11,6 & 0,0 & 33,3 & 0,0 & 66,7 & 0,0 & 0,0 & 100,0 & 0,0 \\
\hline $\begin{array}{l}\text { 3. Proximidade com } \\
\text { os fornecedores de } \\
\text { insumos e matéria } \\
\text { prima } \\
\text { 4. Proximidade com }\end{array}$ & 0,0 & 61,5 & 19,2 & 19,3 & 0,0 & 100,0 & 0,0 & 0,0 & 0,0 & 100,0 & 0,0 & 0,0 \\
\hline $\begin{array}{l}\text { os } \\
\text { clientes/consumidores }\end{array}$ & 0,0 & 61,5 & 30,8 & 7,7 & 0,0 & 100,0 & 0,0 & 0,0 & 0,0 & 100,0 & 0,0 & 0,0 \\
\hline $\begin{array}{l}\text { 5. Infraestrutura física } \\
\text { (energia, transporte, } \\
\text { comunicações) }\end{array}$ & 0,0 & 84,6 & 15,4 & 0,0 & 0,0 & 66,7 & 33,3 & 0,0 & 0,0 & 100,0 & 0,0 & 0,0 \\
\hline $\begin{array}{l}\text { 6. Proximidade com } \\
\text { produtores de } \\
\text { equipamentos }\end{array}$ & 0,0 & 96,2 & 3,8 & 0,0 & 0,0 & 100,0 & 0,0 & 0,0 & 0,0 & 100,0 & 0,0 & 0,0 \\
\hline $\begin{array}{l}\text { 7. Disponibilidade de } \\
\text { serviços técnicos } \\
\text { especializados } \\
\text { 8. Existência de }\end{array}$ & 0,0 & 100,0 & 0,0 & 0,0 & 0,0 & 100,0 & 0,0 & 0,0 & 0,0 & 100,0 & 0,0 & 0,0 \\
\hline $\begin{array}{l}\text { programas de apoio e } \\
\text { promoção }\end{array}$ & 0,0 & 80,8 & 19,2 & 0,0 & 0,0 & 66,7 & 33,3 & 0,0 & 0,0 & 100,0 & 0,0 & 0,0 \\
\hline $\begin{array}{l}\text { 9. Proximidade com } \\
\text { universidades e } \\
\text { centros de pesquisa }\end{array}$ & 3,8 & 76,9 & 15,5 & 3,8 & 0,0 & 100,0 & 0,0 & 0,0 & 0,0 & 0,0 & 100,0 & 0,0 \\
\hline 10. Outra & 0,0 & 0,0 & 0,0 & 0,0 & 0,0 & 0,0 & 0,0 & 0,0 & 0,0 & 0,0 & 0,0 & 0,0 \\
\hline
\end{tabular}

Fonte: Elaborado pelo autor (2017).

Source: Prepared by the author (2017).

Em relação à infraestrutura (energia, transporte e comunicações), de uma maneira geral a avaliação feita pelas empresas pesquisadas considerou infraestrutura insuficiente para sustentar a competitividade do turismo desenvolvido localmente. Itens como energia, transporte e comunicações obtiveram, respectivamente as seguintes avaliações: (i) Microempresas $84,6 \%$ baixa e 15,4\% média importância; (ii) pequenas empresas 66,7\% baixa e 33,3\% média importância; e (iii) médias empresas apontaram como $100,0 \%$ de baixa importância. 
A proximidade com os fornecedores de insumos e matéria prima e com os clientes/consumidores guarda certa similaridade na percepção dos entrevistados. Denotando insuficiente oferta de insumos e matéria prima, tanto quanto se observa a proximidade com os consumidores. Neste caso, a localização geográfica do município de Itacaré confere algumas explicações para estes fatos: a sede do município não se configura como uma cidade polarizada, e verifica-se uma convergência comercial para outros municípios, em especial, para as cidades de Ilhéus e Itabuna que abastecem os meios de hospedagem de Itacaré, com produtos e serviços mais utilizados por estes empreendimentos.

Diferentes fatores dificultam a constituição de um arranjo produtivo local numa determinada localidade. $\mathrm{Na}$ avaliação sobre as principais desvantagens relacionadas com a localização das empresas no arranjo, quatro fatores foram avaliados negativamente: (i) Disponibilidade de mão de obra qualificada; (ii) Proximidade com produtores de equipamentos; e (iii) disponibilidade de serviços técnicos especializados.

A proximidade com produtores de equipamentos e a disponibilidade de serviços técnicos especializados realçam a questão da centralidade do local no aspecto da oferta de bens e serviços com nível tecnológico superior e/ou especializados. Essa oferta é suprida por empresas sediadas em grandes mercados, com destaque para São Paulo, Rio de Janeiro, Belo Horizonte e Salvador, capital do estado.

A existência de programas de apoio e promoção para as empresas do setor, pode-se revelar como fator propulsor ou inibidor para se estabelecer uma competitividade sistêmica no APL de Itacaré. Especificamente, quando se observa os resultados colhidos junto as empresas que participaram da pesquisa, esta externalidade, pode ser considerada como negativa $(80,8 \%$, $66,7 \%$ e $100,0 \%$ baixa importância para as microempresas, pequenas e médias empresas, respectivamente.

Estas evidências constituem-se em fatores que deverão ser potencializados para se obter uma melhor performance no arranjo, visando a sua consolidação e longevidade. Algumas delas tem forte apelo no estabelecimento de um padrão para a cooperação, interação, aprendizado e inovação. Fatores determinantes para o fortalecimento de arranjos produtivos locais.

Os dados da pesquisa apontam para o fato de que a principal transação comercial das empresas do arranjo realizadas localmente é a aquisição de insumos. Destaca-se, também, aquisição de componentes e peças. Quanto à aquisição de equipamentos e de serviços de manutenção, marketing, contabilidade, informática, entre outros, algumas empresas realizam a aquisição desses produtos e serviços na cidade de llhéus, distante aproximadamente $65 \mathrm{~km}$ de Itacaré, ou Itabuna, distante 100,3 km desta localidade. Itabuna é considerada uma cidade polarizada, que conta com a presença de grandes atacadistas, concessionárias e fornecedores especializados. De acordo com os entrevistados, quando se trata de equipamentos mais sofisticados tecnologicamente ou de certa especificação para a indústria do turismo local, essa aquisição é consumada nos grandes 
centros do estado ou fora dele.

Quanto às vendas de produtos turísticos, no caso específico dos meios de hospedagem, as referidas vendas são realizadas em regra geral pelas operadoras de turismo, que atuam no território brasileiro, incluindo também, em menor escala, de operadoras internacionais. Verifica-se, também, a participação significativa na comercialização e reservas através dos sites das pousadas e hotéis, operacionalizados pelas próprias empresas. Desta forma, a venda local tem baixa aprovação na avalição das empresas pesquisadas.

Notadamente, a articulação de projetos que contribuam para aumentar a competitividade sistêmica de cadeias produtivas e empresas, que atuem no setor turístico, é necessária para a aceleração e sustentabilidade do processo de desenvolvimento local. Nesse sentido, ganhou destaque a promoção de ações sobre arranjos produtivos locais, sendo necessárias ações orientadas para a constituição e o fortalecimento de arranjos produtivos que visem ao fortalecimento da cooperação e do aprendizado para a inovação.

Pode-se observar na Tabela 5 a necessidade de avaliação de sindicatos, associações, cooperativas locais quanto à interação dos atores locais, que compõem o APL. Os dados revelam que a interação entre as empresas e as instituições representativas em Itacaré, têm sido pouco expressiva e se apresenta dispersa. Tal situação mostra que é necessária a cooperação de instituições formais e informais para criar e fomentar um ambiente de cooperação, mesmo na presença de competição entre elas.

Conforme Tabela 5 as microempresas consideraram de baixa importância o item que se refere ao auxílio na definição de objetivos comuns para o arranjo produtivo (65,5\%). Nas pequenas e médias empresas há uma confirmação dessa observação, configurando-se este item com 100,0\% baixa importância. Outro fator a ser destacado, neste contexto, foi a avaliação sobre promoção de ações cooperativas destas instituições, onde $69,2 \%$ das microempresas avaliaram como baixa importância. O percentual apontado pela pequena empresa foi de $66,7 \%$, também, para baixa importância. Já na média empresa essa percepção foi negativa, ficando registrado $100,0 \%$ baixa importância.

Em arranjos produtivos locais, identificam-se diferentes tipos de cooperação entre as empresas e alguns atores do arranjo produtivo, incluindo a cooperação produtiva e a cooperação inovativa. A cooperação pode ocorrer, envolvendo empresas e outras instituições, por meio de programas de treinamento, realização de eventos e feiras, cursos e seminários, projetos de viabilidade técnica e projetos de fomento, conforme já abordado nas seções anteriores.

Neste sentido, duas contribuições endossam a percepção do reduzido nível de cooperação entre as instituições e as empresas que conformam o arranjo: (i) Promoção de ações dirigidas a capacitação tecnológica de empresas e, (ii) Estímulo ao desenvolvimento do sistema de ensino e pesquisa local. Observados a baixa importância atribuídas pelas empresas 
participantes da pesquisa, mesmo em detrimento ao porte das empresas pesquisadas (Tabela 5).

Tabela 5: Avaliação da contribuição de sindicatos, associações, cooperativas locais (\%).

Table 5: Evaluation of the contribution of unions, associations, local cooperatives (\%).

\begin{tabular}{|c|c|c|c|c|c|c|c|c|c|c|c|c|}
\hline \multirow{2}{*}{ Tipo de Contribuição } & \multicolumn{4}{|c|}{ Micro } & \multicolumn{4}{|c|}{ Pequena } & \multicolumn{4}{|c|}{ Média } \\
\hline & Nula & Baixa & Média & Alta & Nula & Baixa & Média & Alta & Nula & Baixa & Média & Alta \\
\hline \begin{tabular}{|l|} 
1. Auxílio na definição \\
de objetivos comuns \\
para o arranjo \\
produtivo
\end{tabular} & 3,8 & 65,5 & 26,9 & 3,8 & 0,0 & 100,0 & 0,0 & 0,0 & 0,0 & 100,0 & 0,0 & 0,0 \\
\hline $\begin{array}{l}\text { 2. Estímulo na } \\
\text { percepção de visões } \\
\text { de futuro para ação } \\
\text { estratégica }\end{array}$ & 7,7 & 61,5 & 30,8 & 0,0 & 0,0 & 100,0 & 0,0 & 0,0 & 0,0 & 100,0 & 0,0 & 0,0 \\
\hline \begin{tabular}{|l|} 
3. Disponibilização de \\
informações sobre \\
matérias-primas, \\
equipamento, \\
assistência técnica, \\
consultoria, etc. \\
\end{tabular} & 7,7 & 73,1 & 15,4 & 3,8 & 0,0 & 100,0 & 0,0 & 0,0 & 0,0 & 100,0 & 0,0 & 0,0 \\
\hline \begin{tabular}{|l|} 
4. Identificação de \\
fontes e formas de \\
financiamento \\
\end{tabular} & 7,7 & 80,8 & 11,5 & 0,0 & 0,0 & 100,0 & 0,0 & 0,0 & 0,0 & 100,0 & 0,0 & 0,0 \\
\hline \begin{tabular}{|l|} 
5. Promoção de \\
ações cooperativas
\end{tabular} & 7,7 & 69,2 & 23,1 & 0,0 & 0,0 & 66,7 & 33,3 & 0,0 & 0,0 & 100,0 & 0,0 & 0,0 \\
\hline $\begin{array}{l}\text { 6. Apresentação de } \\
\text { reivindicações } \\
\text { comuns } \\
\end{array}$ & 7,7 & 53,8 & 26,9 & 11,5 & 0,0 & 66,7 & 33,3 & 0,0 & 0,0 & 100,0 & 0,0 & 0,0 \\
\hline \begin{tabular}{|l|} 
7. Criação de fóruns e \\
ambientes para \\
discussão
\end{tabular} & 7,7 & 61,5 & 30,8 & 0,0 & 0,0 & 0,0 & 100,0 & 0,0 & 0,0 & 100,0 & 0,0 & 0,0 \\
\hline $\begin{array}{l}\text { 8. Promoção de } \\
\text { ações dirigidas a } \\
\text { capacitação } \\
\text { tecnológica de } \\
\text { empresas }\end{array}$ & 7,7 & 61,5 & 30,8 & 0,0 & 0,0 & 100,0 & 0,0 & 0,0 & 0,0 & 100,0 & 0,0 & 0,0 \\
\hline $\begin{array}{l}\text { 9. Estímulo ao } \\
\text { desenvolvimento do } \\
\text { sistema de ensino e } \\
\text { pesquisa local } \\
\end{array}$ & 7,7 & 80,8 & 11,5 & 0,0 & 0,0 & 100,0 & 0,0 & 0,0 & 0,0 & 100,0 & 0,0 & 0,0 \\
\hline $\begin{array}{l}\text { 10. Organização de } \\
\text { eventos técnicos e } \\
\text { comerciais }\end{array}$ & 7,7 & 53,8 & 38,5 & 0,0 & 0,0 & 100,0 & 0,0 & 0,0 & 0,0 & 100,0 & 0,0 & 0,0 \\
\hline
\end{tabular}

Fonte: Elaborado pelo autor.

Source: Prepared by the author.

Quanto à cooperação de órgãos públicos, no âmbito do governo federal, verifica-se baixa participação e interação entre as empresas do arranjo e os órgãos públicos voltados para o setor turístico. Os itens referentes ao conhecimento e a participação em algum tipo de programa ou ações realizadas na esfera federal, apontam neste caminho: 57,7\% das microempresas responderam que não tem conhecimento e 30,8\% conhecem, mas não participam de tais ações. Apenas, $11,5 \%$ das 
microempresas do arranjo tem conhecimento e participa das ações do governo federal. Para as médias empresas que participaram da pesquisa, $66,7 \%$ não conhecem e $33,3 \%$ conhecem e não participam de tais programas. No outro lado da dimensão empresarial, no caso das médias empresas, 100,0\% conhecem e participam.

Quando indagadas em relação aos programas/ações no nível estadual, os escores situaram-se no seguinte nível: (i) as microempresas apontaram $61,6 \%$ que não conhecem, 19,2\% conhecem, mas não participam e $19,2 \%$ conhecem e participam; e (ii) as pequenas $66,7 \%$ não conhecem e $33,3 \%$ conhecem e participam; e (iii) as médias empresas 100,0\% não conhecem tais programas ou ações voltadas para o setor. Verifica-se, também, a mesma percepção em relação a atuação dos atores públicos no nível local.

Outras instituições revelam-se importantes para o estabelecimento da cooperação e interação entre os atores econômicos, sociais e políticos de uma localidade. Desta forma, os resultados obtidos referentes ao conhecimento e a participação, em algum tipo de programa ou ações realizadas pelo SEBRAE, o escore consignado foi registrado da seguinte forma: (i) as microempresas $11,5 \%$ não conhece, $46,2 \%$ conhecem, mas não participam e $42,3 \%$ conhecem e participam; (ii) as pequenas empresas $100,0 \%$ conhecem e participam; e (iii) as médias empresas 100,0\% não conhecem programas ou ações realizadas pelo SEBRAE, para as MPEs do setor.

$\mathrm{Na}$ categoria "outras instituições", as microempresas atribuíram os seguintes escores: $50,0 \%$ não conhece, $15,4 \%$ conhecem, mas não participam e 34,6\% conhecem e participam. As pequenas empresas atribuíram da seguinte forma: $66,7 \%$ não conhecem e 33,3\% conhecem e participam. Já para as médias empresas 100,0\% conhecem, mas não participam das ações promovidas por outras instituições, entre elas, pode-se destacar as associações, clubes de dirigentes lojistas, sindicatos laborais e patronais, entre outas instituições representativas sediadas em Itacaré.

A fim de corroborar com a percepção do grau de interação e o nível de cooperação estabelecidos no arranjo, as avaliações desses programas guardam relação coerente com os resultados apontados acima, quanto aos programas ou ações específicas para o segmento turístico desta localidade, oferecidos tanto pelo setor público quanto instituições do setor privado.

As relações formais e informais constituídas entre os setores produtivos e a rede de instituições públicas e privadas revelam-se muito especiais e de caráter específico a cada APL, sendo resultado da trajetória de evolução de cada território e arranjo produtivo, conforme já abordado anteriormente. O desempenho de cada arranjo poderá ser induzido por iniciativas de mobilização e organização de instâncias de governança, sendo, hoje, mais recorrentes nas políticas públicas para APLs.

As empresas participantes da pesquisa demonstraram convergência na escolha dos principais fatores, que possam contribuir para o desempenho de cada firma no mercado. A competitividade da empresa pode ser 
transformada em competitividade sistêmica, influenciando o adensamento da aglomeração produtiva e, também, no posicionamento mercadológico do APL de Turismo de Itacaré.

Destacaram-se os programas de capacitação profissional e treinamento técnico, juntamente com a melhoria na educação básica. Esses programas tiveram praticamente a unanimidade das empresas participantes desta pesquisa. Associados aos programas de apoio a consultoria técnica e à oferta de serviços tecnológicos, podem formar um arcabouço que transformem a capacitação e inovação nas empresas, em diferencial competitivo do próprio APL.

\section{Práticas ambientais no arranjo produtivo}

De acordo com WTO o turismo sustentável, deve-se constituir em uma atividade que atenda as "necessidades dos turistas e as necessidades socioeconômicas das regiões receptoras, enquanto a integridade cultural, a integridade dos ambientes naturais, e a diversidade biológica são mantidas para o futuro" (BRASIL, 2010, p. 30). Com a intenção de aprofundar os conceitos e práticas ambientais, a pesquisa aprofundou a investigação realizada com os atores econômicos, que atuam na cadeia produtiva do turismo na região e, deste modo, apresentam-se nas Tabelas 6 e 7, os itens que dialogam com a preservação ambiental, nesta localidade.

Vários fatores são determinantes para o desempenho do APL de Turismo de Itacaré, como observado anteriormente, entre eles destacam-se: cooperação, interação, inovação, o apoio das instituições locais, 0 conhecimento tácito que se desenvolve nas aglomerações produtivas, entre outros. Vale ressaltar, a necessidade de se adicionar às dimensões econômicas e sociais, iniciativas e ações que visem desenvolver as atividades econômicas de modo sustentável. Constata-se que toda atividade exercida pelo ser humano, causa algum dano ao meio ambiente. Portanto, não seria diferente com a atividade turística. Sendo assim, buscou-se investigar tal fenômeno junto aos atores locais que atuam na cadeia produtiva do turismo em Itacaré.

A Tabela 6, apresenta os resultados das ações empreendidas nas empresas pesquisadas, apontam para uma razoável presença de ações proativas, que contribuam para a sustentabilidade ambiental no arranjo. Por exemplo, na descrição relativa a redução do consumo de água, os resultados apontam boas práticas ambientais, sendo que: (i) as microempresas consignaram com 30,8\% média e 53,8\% alta importância para este item; (ii) as pequenas empresas com 33,3\% média e $66,7 \%$ alta importância; e (iii) as médias empresas 100,0\% alta importância, para esse tipo de medida. Verifica-se, na pesquisa realizada, um desempenho ainda melhor para a redução do consumo de energia elétrica (50,0\% alta importância para as microempresas e 100,0\% alta importância para as pequenas e médias empresas), revelando uma similaridade nas medidas adotadas pelos meios de hospedagem do arranjo, para esses dois itens.

Pode-se verificar que duas medidas tiveram desempenho 
insatisfatório nas ações desenvolvidas pelas micro e pequenas empresas: (i) Redução, reutilização e reciclagem de resíduos sólidos, com 30,8\% nula e $46,2 \%$ baixa importância para as microempresas e, $66,7 \%$ baixa importância para as pequenas empresas; e (ii) coleta seletiva, com $34,6 \%$ nula e $38,5 \%$ baixa importância para as microempresas e $66,7 \%$ nula e $33,3 \%$ baixa importância para as pequenas empresas (Tabela 6). Entretanto, consignouse com $100,0 \%$ de alta importância para estas duas práticas ambientais, na pesquisa, pelas médias empresas do APL de Turismo de Itacaré.

Tabela 6: Ações que a empresa adota em relação às práticas ambientais.

Table 6: Actions that the company adopts in relation to environmental practices.

\begin{tabular}{|c|c|c|c|c|c|c|c|c|c|c|c|c|}
\hline \multirow{2}{*}{ Características } & \multicolumn{4}{|c|}{ Micro } & \multicolumn{4}{|c|}{ Pequena } & \multicolumn{4}{|c|}{ Média } \\
\hline & Nula & Baixa & Média & Alta & Nula & Baixa & Média & Alta & Nula & Baixa & Média & Alta \\
\hline $\begin{array}{l}\text { 1. Redução do } \\
\text { Consumo de } \\
\text { Água }\end{array}$ & 0,0 & 15,4 & 30,8 & 53,8 & 0,0 & 0,0 & 33,3 & 66,7 & 0,0 & 0,0 & 0,0 & $100, c$ \\
\hline $\begin{array}{l}\text { 2. Redução do } \\
\text { Consumo de } \\
\text { Energia Elétrica }\end{array}$ & 0,0 & 15,4 & 34,6 & 50,0 & 0,0 & 0,0 & 0,0 & 100,0 & 0,0 & 0,0 & 0,0 & $100, c$ \\
\hline $\begin{array}{l}\text { 3.Aproveitamento } \\
\text { da Água da } \\
\text { Chuva }\end{array}$ & 57,7 & 7,7 & 7,7 & 26,9 & 100,0 & 0,0 & 0,0 & 0,0 & 0,0 & 0,0 & 100,0 & 0,0 \\
\hline & 30,8 & 46,2 & 15,4 & 7,7 & 0,0 & 66,7 & 33,3 & 0,0 & 0,0 & 0,0 & 0,0 & $100, c$ \\
\hline $\begin{array}{l}\text { 5. Redução da } \\
\text { Emissão de } \\
\text { Gases e Odores }\end{array}$ & 38,5 & 19,2 & 23,1 & 19,2 & 0,0 & 0,0 & 33,3 & 66,7 & 0,0 & 0,0 & 0,0 & $100, c$ \\
\hline 6. Coleta Seletiva & 34,6 & 38,5 & 23,1 & 3,8 & 66,7 & 33,3 & 0,0 & 0,0 & 0,0 & 0,0 & 0,0 & $100, c$ \\
\hline $\begin{array}{l}\text { medidas } \\
\text { referentes a } \\
\text { estes itens }\end{array}$ & 0,0 & 38,5 & 61,5 & 0,0 & 0,0 & 0,0 & 100,0 & 0,0 & 0,0 & 0,0 & 0,0 & $100, c$ \\
\hline
\end{tabular}

Fonte: Elaborado pelo autor (2017).

Source: Prepared by the author (2017).

Atribui-se melhor desempenho nesses dois quesitos, a presença de várias organizações não governamentais (ONGs), que atuam na proteção ao meio ambiente, retirando esses resíduos e fazendo a gestão da sua reutilização. Vale salientar, quanto a coleta seletiva que o município não realiza este tipo de coleta. Ficando a cargo das ONGs a retirada desse material. O destino, especialmente da matéria orgânica, são as hortas comunitárias e, também, direcionados para a prática da agroecologia.

Quanto a redução da emissão de gases e odores, essa medida tem um grau de efetividade razoável, em função do conforto que os meios de hospedagem oferecem aos seus clientes. Evita-se o dissabor de impregnar as pousadas, hotéis e os resorts com odores desagradáveis para os seus hóspedes.

Como salientado, o turismo pode causar impactos positivos como: aumento da produção, consumo, emprego e renda na esfera privada, bem 
como melhorar a arrecadação e os gastos no setor público. Entretanto, também pode gerar uma série de malefícios, refletidas em "cicatrizes na paisagem" ocasionadas pela instalação dos equipamentos turísticos nas áreas naturais, diante de um fluxo e volume de visitantes que impactem negativamente os ecossistemas, especialmente, os mais frágeis e vulneráveis encontrados no município de Itacaré. Neste contexto, as ações que as empresas do arranjo promovem em relação às práticas ambientais estão apresentadas na Tabela 7.

Tabela 7: Práticas ambientais adotadas pela empresa.

Table 7: Environmental practices adopted by the company.

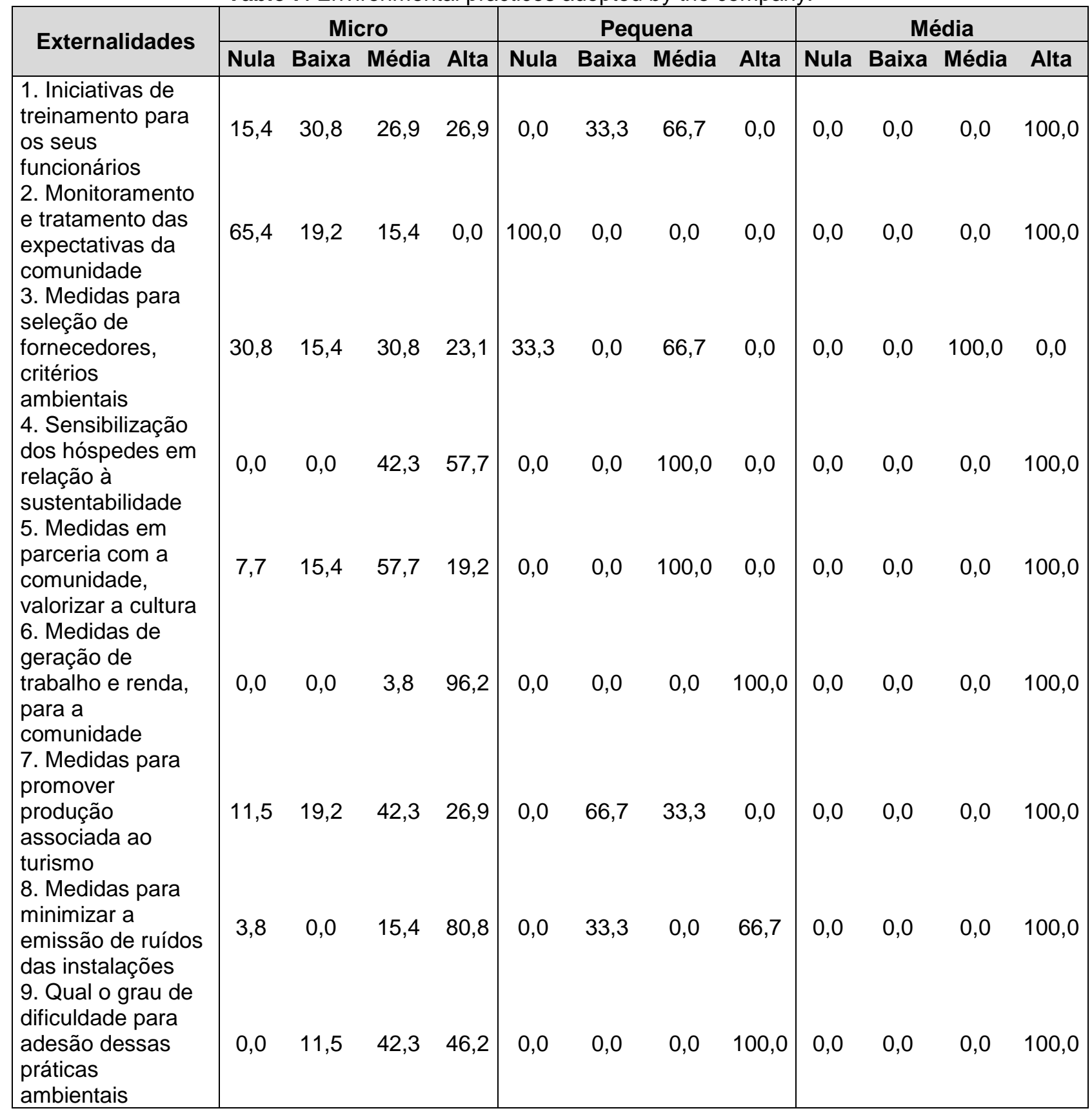

Fonte: Elaborado pelo autor.

Source: Prepared by the author. 
Assim, quando perguntados se o hotel adota iniciativas de treinamento para seus funcionários, referente à conscientização ambiental, a ponto de promover pequenas modificações em seu comportamento. As respostas produzidas pelas microempresas retratam a seguinte percepção: $15,4 \%$ nula, $30,8 \%$ baixa, $26,9 \%$ média e $26,9 \%$ alta importância. As respostas denotam certa dispersão de ações proativas em prol da sustentabilidade ambiental. As respostas obtidas tanto na pequena quanto na média empresa, são mais consistentes e retratam as seguintes ações: (i) na pequena as práticas situam-se nestas magnitudes 33,3\% baixa e 66,7\% média importância; (ii) na média empresa configuram-se assim: 100,0\% alta importância. Neste contexto, a disseminação das boas práticas ambientais no turismo, reveste-se de grande importância pela interação que possa ocorrer entre os funcionários dos meios de hospedagem e os turistas.

Outro fator que merece destaque, trata-se da relação das empresas do setor com a comunidade do entorno. Nesta descrição, elencada na Tabela 7, percebe-se ausência de ações que promovam medidas para 0 monitoramento e tratamento das expectativas e impressões dos moradores da comunidade em relação aos serviços ofertados, incluindo meios para pesquisar opiniões, reclamações e sugestões. A exceção é uma média empresa do arranjo, que mantêm política sistêmica de relação com a comunidade do entorno.

Vale salientar, que essas medidas poderiam nortear ações de mitigação dos impactos gerados pelo próprio equipamento e, também, gerar a possibilidade de mediação nos conflitos ocasionados pelos visitantes na comunidade receptora. Principalmente, quando associado com a questão anterior, que trata da qualificação e treinamento dos funcionários com relação as questões ambientais. Os funcionários das pousadas, hotéis e resorts da região, podem se transformar em difusores das boas práticas ambientais, promovendo a cultura local, entre outras ações proativas para o bem-estar da comunidade receptora e dos turistas.

O encadeamento das atividades que conformam a cadeia produtiva do turismo, poderiam contribuir para o meio ambiente. Pela atuação e compartilhamento de ações positivas que promovam boas práticas ambientais. Neste aspecto, as empresas pesquisadas demonstraram, na pesquisa, mediana atitude em relação a seleção de fornecedores, considerando critérios ambientais, socioculturais e econômicos, que busquem a promoção da sustentabilidade na comunidade. As respostas mais representativas situaram-se em baixa e média importância para este quesito.

Duas práticas foram, novamente, bem avaliadas pelas empresas do arranjo, especificamente, as relacionadas a sensibilização dos hóspedes em relação a sustentabilidade e as medidas que visam a parceria com a comunidade, que tem forte apelo na preservação do meio ambiente, valorização da cultura local e apoio ao comércio de produtos e serviços da região

Destaca-se, também, aqui, as ações promovidas pelos empreendimentos hoteleiros de Itacaré quanto as medidas adotas para 
geração de trabalho e renda, para a comunidade local. Este resultado revela-se positivo, tendo um percentual de alta importância variando entre $96,2 \%$ e $100 \%$, nas empresas pesquisadas que compuseram a amostra.

O aspecto relacionado a promoção artesanal, agropecuária ou industrial, associada ao turismo e que possua atributos naturais ou culturais da região e que são capazes de agregar valor ao produto turístico, foi avaliado de forma moderada para promover a valorização desses produtos, trazendo, por conseguinte, melhores resultados econômicos e sociais para a comunidade local.

Já no aspecto do conforto dos hóspedes e da comunidade, de acordo com os escores assinalados na Tabela 7 , em sua maioria, variando apenas a intensidade, os hotéis adotam medidas para minimizar a emissão de ruídos das instalações, maquinário e equipamentos, das atividades de lazer e entretenimento de modo a não perturbar o ambiente natural, o conforto dos hóspedes e a comunidade local.

Como já mencionado, os resultados das ações empreendidas nas empresas do arranjo, demonstram razoável presença de ações proativas, que contribuam para a sustentabilidade do turismo na localidade pesquisada. Este fato pode ser corroborado pelo resultado obtido no item 9, da Tabela 7, onde ficou claro o grau de dificuldade atribuído pelos gestores dos meios de hospedagem na adoção dessas práticas ambientais. As empresas participantes da pesquisa apontaram para um percentual de alta importância variando entre 46,2\% e 100\%.

Deste modo, a preocupação com os impactos da relação sociedade versus natureza sobre o meio ambiente no contexto do turismo, vem exigindo a busca por meios para eliminar ou pelo menos mitigar os impactos negativos decorrentes das ações antrópicas. Esse tema, já abordado nas seções anteriores, remete para a necessidade do controle e planejamento das atividades turísticas desenvolvidas no Arranjo Produtivo Local do Turismo de Itacaré.

Uma alternativa na esfera do planejamento turístico está baseada na criação, desenvolvimento e aplicação de sistemas ou ferramentas de avaliação que possam mensurar a sustentabilidade do turismo e, neste caso específico, do turismo realizado na Bahia.

\section{Considerações Finais}

O objetivo desse trabalho foi analisar a sustentabilidade ambiental do turismo no município de Itacaré, Bahia, sob a ótica do desenvolvimento local. Observou-se na discussão dos aglomerados produtivos os procedimentos metodológicos de análise de APLs, como fator de desenvolvimento local. Nesse contexto, verificou-se a existência de uma estrutura produtiva significativa desta atividade no município estudado. Diante das análises realizadas, concluiu-se que a localidade estudada pode ser identificada como APL de turismo em fase de consolidação, com moderado adensamento das atividades que conformam a cadeia produtiva do turismo de Itacaré. 
É necessário frisar as dificuldades de cooperação e interação no APL de Turismo de Itacaré. Concluiu-se que é recomendável uma articulação entre os diferentes atores envolvidos com o APL, para seu efetivo desenvolvimento e sua sustentabilidade. Somente com essa articulação e a consequente formação de um arranjo produtivo consolidado será factível minimizar os impactos negativos ocasionados pela atividade turística, bem como maximizar os benefícios econômicos e sociais.

Constatou-se que o impacto é maior nos aspectos qualitativos do que quantitativos, na conformação do arranjo produtivo local de turismo. Identificou-se como importante elevar o nível de competitividade das firmas, estimular o ambiente inovador, implementar novos processos de gestão e, espera-se uma maior mobilização das forças locais para o desenvolvimento deste APL.

$\mathrm{Na}$ dimensão ambiental verificou-se a necessidade de implementação de ações, públicas e privadas, que direcionem e potencializem medidas que elevem a atividade turística de forma sustentável. Especificamente, relacionadas a redução do consumo de água e energia, aproveitamento da água da chuva, gerenciamento de resíduos sólidos e implementação de coleta seletiva. Os resultados das ações empreendidas nas empresas pesquisadas apontam para razoável presença de ações proativas, que contribuam para a sustentabilidade ambiental no arranjo.

Espera-se como resultado deste trabalho: (i) melhorar a compreensão nos aspectos teóricos e práticos do desenvolvimento sustentável; (ii) contribuir para a análise das políticas de desenvolvimento regional, particularmente, na localidade pesquisada; e, (iii) subsidiar 0 desenvolvimento de políticas públicas direcionadas ao desenvolvimento sustentável do turismo.

\section{Referências}

ALBAGLI, S.; BRITO, J. Glossário de arranjos e sistemas produtivos e inovativos locais. Rede de Pesquisa em Sistemas Produtivos e Inovativos Locais. Rio de Janeiro: RedeSist, 2003.

ALBERTI, F.G.; GIUSTI, J.D. Cultural heritage, tourism and regional competitiveness: the Motor Valley cluster. City, Culture and Society, v. 3, p. 261-273, 2012.

ARSEZEN-OTAMIS, P.; YUZBASIOGLU, N. Analysis of antalya tourism cluster perceived performance with structural equation model. Procedia Social and Behavioral Sciences, v. 99, p. 682-690, 2013.

BENI, M. C. Análise estrutural do turismo. São Paulo: Senac, 2002.

BRASIL. Ministério do Turismo (MTUR). Secretaria Nacional de Políticas de Turismo. Ecoturismo: orientações básicas. 2. ed. Brasília, DF: MTUR, 2010.

BRASIL Ministério do Turismo (MTUR). Matriz de classificação de meios de hospedagem: sistema de classificação de meios de hospedagem SBClass. Brasília, DF: MTUR, 2011. 
BRASIL. Ministério do Turismo (MTUR). Programa de regionalização do turismo: categorização dos municípios das regiões turísticas do mapa do turismo brasileiro. Brasília, DF: MTUR, 2015.

BRASIL. Ministério do Trabalho e Emprego (MTE). Relação Anual de Informações Sociais (Rais) de 2015. Disponível em: < http://pdet.mte.gov.br/acesso-on-line-as-bases-de-dados/>. Acesso em: 14 fev. 2017.

BRITO, J. Relevância de PMEs em arranjos produtivos na indústria brasileira: uma análise exploratória a partir de dados da RAIS. Rio de Janeiro: Redesist. I.E./UFRJ, 2002. Disponível em: <www.ie.ufrj.br/redesist>. Acesso em: 12 ago. 2006.

BRUNA, G.C. et al. Indicadores de sustentabilidade no planejamento de arranjos produtivos locais. In: PHILIPPI Jr, A.; MALHEIROS, T.F. Indicadores de sustentabilidade e gestão ambiental. Barueri, SP: Manole, 2012.

CALIMAN, O. Subsídio para a formulação de uma política de desenvolvimento regional para o Espírito Santo. Texto para discussão. Vitória: 2003. (Mimeografado).

CASSIOLATO, J.E.; LASTRES, H.M.M.; STALLIVIERI, F. Introdução: Políticas estaduais e mobilização de atores políticos em arranjos produtivos e inovativos locais. In: CASSIOLATO, J.E.; LASTRES, H.M.M.; STALLIVIERI, F. (Org.). Arranjos produtivos locais: alternativa para o desenvolvimento: experiências de políticas. Rio de Janeiro: E-papers, 2008.v.2.

CLASSIFICAÇÃO NACIONAL DE ATIVIDADES ECONÔMICAS (CNAE). 5510-8/01.

COMISIÓN ECONÓMICA PARA AMÉRICA LATINA Y EL CARIBE (CEPAL). Indicadores de sostenibilidad ambiental y de desarrollo sostenible: estado del arte y perspectivas. Santiago de Chile: Naciones Unidas, 2001.

COSTA, H.A.; COSTA, A C.; MIRANDA Jr., N.S. Arranjos Produtivos Locais (APL) no Turismo: estudo sobre a Competitividade e o Desenvolvimento Local na Costa dos Corais - AL. Observatório de Inovação do Turismo Revista Acadêmica, Rio de Janeiro: EBAPE, FGV, v. VII, n. 1, p. 1-21, abr. 2012.

CROCCO, M. A. et al. Metodologia de identificação de aglomerações produtivas locais. Nova Economia: Revista do Departamento de Ciências Econômicas, UFMG, Belo Horizonte, MG. v. 16, n. 2, p. 211-241, 2006.

CRUZ, S.H.R; MENDES, F.L.S.; CAMPOS, R.I.R. Ecoturismo e desenvolvimento local na Floresta Nacional de Caxiuanã/Melgaço (PA). Revista Brasileira de Ecoturismo, São Paulo, v.9, n.6, nov-2016/jan-2017, pp.737-750.

DE SORDI, J. O.; MEIRELES, M. Arranjo produtivo local ou aglomerado de empresas? Distinção por atributos associados à temática transferência de informação. Revista de Administração Pública, Rio de Janeiro, v. 46, n. 3, p. 775-794, maio/jun. 2012. 
DENCKER, A.F.M. Métodos e técnicas de pesquisa em turismo. São Paulo: Futura, 1998.

FERREIRA, M.T.S. et. al. Análise do desenvolvimento de Arranjos Produtivos Locais (APLs): um estudo de caso do município de Paraty (RJ). Revista de Administração Pública - RAP, Rio de Janeiro, v. 45, n. 2, p. 517-39, mar./abr. 2011.

GIL, A.C. Como elaborar projetos de pesquisa. 5. ed. São Paulo: Atlas, 2010.

HADDAD, P.R. Medidas de Localização e de Especialização. In: HADDAD, P.R. (Org.). Economia regional: teorias e métodos de análise. Fortaleza: BNB, 1989.

HANAI, F.Y.; ESPÍNDOLA, E.L.G. Indicadores de sustentabilidade para desenvolvimento turístico. In: PHILIPPI Jr, A.; MALHEIROS, T.F. Indicadores de sustentabilidade e gestão ambiental. Barueri, SP: Manole, 2012.

INSTITUTO BRASILEIRO DE GEOGRAFIA E ESTATÍSTICA (IBGE). Indicadores de desenvolvimento sustentável. Rio de Janeiro: IBGE, 2000.

INSTITUTO BRASILEIRO DE GEOGRAFIA E ESTATÍSTICA (IBGE). @Cidades. Histórico dos municípios. Disponível em: $<$ http://www.cidades.ibge.gov.br/xtras/perfil.php?lang=\&codmun=292530\&se arch=bahia|porto-seguro>. Acesso em: 15 fev. 2017.

LASTRES, H.M.M.; CASSIOLATO, J.E. Novas políticas na era do conhecimento: o foco em arranjos produtivos e inovativos locais. Rede de Pesquisa em Sistema Produtivos Locais do Instituto de Economia da Universidade Federal do Rio de Janeiro - Redesist. 2003. Disponível em: $<$ www.ie.ufri.br/redesist $>$. Acesso em: 06 abr. 2017

MALHEIROS, T.F.; COUTINHO, S.M.V.; PHILIPPI Jr, A. Indicadores de sustentabilidade: uma abordagem conceitual. In: PHILIPPI Jr, A.; MALHEIROS, T.F. Indicadores de sustentabilidade e gestão ambiental. Barueri, SP: Manole, 2012.

MARINI, M. Jr.; SILVA, C.L.; NASCIMENTO, D.E. Políticas públicas e arranjos produtivos locais: uma análise baseada na participação das esferas públicas. Revista Brasileira de Gestão e Desenvolvimento Regional, Taubaté, SP, Brasil, v. 12, n. 1, p. 311-330, jan./abr. 2016.

MOREIRA, B.C.M.; FERNANDES, D. A.; DIAS JUNIOR, C. M. Análise do aglomerado produtivo das indústrias têxteis do município de Formiga (MG). Revista Brasileira de Gestão e Desenvolvimento Regional, Taubaté, SP, Brasil, v. 13, n. 2, p. 3-25, maio/ago. 2017.

MOREIRA, S.B. Sobre a medição da componente ambiental do desenvolvimento: principais abordagens e indicadores. Desenvolvimento e Meio Ambiente, UFPR, v. 27, p. 121-132, jan./jun. 2013.

ORGANIZAÇÃO MUNDIAL DO TURISMO (OMT). Recomendações Internacionais de Estatísticas de Turismo (RIS). 2008. 
PARR, J.B. Agglomeration economies: ambiguities and confusions. Environment and Planning A, v. 34, p. 717-731, 2002.

PORTER, M.E. Clusters and the new economics of competition. Harvard Business Review, Cambridge, v. 76, n. 6, p. 77-90, nov./dec. 1998.

PROGRAMA DAS NAÇÕES UNIDAS PARA O DESENVOLVIMENTO (PNUD). O índice de desenvolvimento humano municipal brasileiro. In: Atlas do desenvolvimento humano no Brasil - 2013. Disponível em <http://www.atlasbrasil.org.br/2013/pt/download/>. Acesso em: 08 ago. 2016.

REED, M.S.; FRASER, E.D.G.; DOUGILL, A.J. An adaptive learning process for developing and applying sustainability indicators with local communities. Ecological Economics, v. 59, p. 406-418, 2006.

SERVIÇO BRASILEIRO DE APOIO A MICRO E PEQUENA EMPRESA (SEBRAE). Cadeia produtiva do turismo: cenários econômicos e estudos setoriais. Recife, PE: SEBRAE, 2008.

SOUZA, D.A.; GIL, A.C. Produção científica nacional sobre clusters turísticos. Revista Turismo - Visão e Ação - Eletrônica, v. 16, n. 3, set./dez. 2014. ISNN: 1983-7151.

SPAOLONSE, E.; MARTINS, S.S.O. Ecoturismo: uma ponte para o turismo sustentável. Revista Brasileira de Ecoturismo, São Paulo, v.9, n.6, p.684698, nov-2016/jan-2017.

TATSCH, A.L.; RUFFONI, J.; BATISTI, V.S.; ROXO, L.A.T. Análise de políticas para aglomerações no Brasil e em países europeus selecionados. Planejamento e Políticas Públicas PPP, n. 44, p. 189-228, jan./jun. 2015.

UNITED NATIONS (UN). Resolution adopted by the General Assembly on 22 December 2015 - A/RES/70/193. International Year of Sustainable Tourism for Development, 2017. NY, 9 February 2016.

VAN BELLEN, H.M. Indicadores de sustentabilidade: uma análise comparativa. 2002. 235p. Tese (Doutorado em Engenharia de Produção) Universidade Federal de Santa Catarina, Santa Catarina, 2002.

VAN BELLEN, H.M. Indicadores de sustentabilidade: uma análise comparativa. 2. ed. Rio de Janeiro: Ed. FGV, 2006.

VERGARA, S.C. Projetos e relatórios de pesquisa em administração. 4. ed. São Paulo: Atlas, 2003.

WORLD TOURISM ORGANIZATION (WTO). Guia de desenvolvimento do turismo sustentável. Porto Alegre: Bookman, 2003.

WORLD TOURISM ORGANIZATION (WTO). Indicadores de desarrollo sostenible para los destinos turísticos: guía práctica. Madrid: UNWTO, 2005.

Nota:

1 Esta pesquisa foi submetida aos princípios éticos, sendo aprovada pelo Comitê de Ética de Pesquisa sob o protocolo nำ1.489.933. 
Wilson Alves de Araújo: Universidade do Estado da Bahia, Eunápolis, BA, Brasil.

E-mail: wilsonaaraujo@gmail.com

Link para o currículo Lattes: http://lattes.cnpq.br/6299500798546420

Mônica de Moura Pires: Universidade Estadual de Santa Cruz, Ilhéus, BA, Brasil.

E-mail:mpires@uesc.br

Link para o currículo Lattes: http://lattes.cnpq.br/6157255488660799

Data de submissão: 09 de agosto de 2017

Data de recebimento de correções: 23 de outubro de 2017

Data do aceite: 23 de outubro de 2017

Avaliado anonimamente 